\title{
Free-fall experiments of volcanic ash particles using a 2-D video disdrometer
}

\author{
Sung-Ho Suh ${ }^{1}$, Masayuki Maki ${ }^{2}$, Masato Iguchi ${ }^{3}$, Dong-In Lee ${ }^{1}$, Akihiko Yamaji $^{4}$, and Tatsuya Momotani ${ }^{4}$ \\ ${ }^{1}$ Department of Environmental Atmospheric Sciences, Pukyong National University, Nam-gu, Busan, Republic of Korea \\ ${ }^{2}$ Research and Education Center for Natural Hazards, Kagoshima University, Korimoto, Kagoshima, Japan \\ ${ }^{3}$ Sakurajima Volcano Research Center, Disaster Prevention Research Institute, Kyoto University, \\ Sakurajima, Kagoshima, Japan \\ ${ }^{4}$ Japan Weather Association, Higashi-Ikebukuro, Toshima, Tokyo, Japan
}

Correspondence: Masayuki Maki (maki@gm.kagoshima-u.ac.jp)

Received: 4 March 2019 - Discussion started: 15 April 2019

Revised: 11 August 2019 - Accepted: 19 August 2019 - Published: 9 October 2019

\begin{abstract}
Information of aerodynamic parameters of volcanic ash particles, such as terminal velocity, axis ratio, and canting angle, are necessary for quantitative ash-fall estimations with weather radar. In this study, free-fall experiments of volcanic ash particles were accomplished using a twodimensional video disdrometer under controlled conditions.

Samples containing a rotating symmetric axis were selected and divided into five types according to shape and orientation: oblate spheroid with horizontal rotating axis $(\mathrm{OH})$, oblate spheroid with vertical axis (OV), prolate spheroid with horizontal rotating axis $(\mathrm{PH})$, prolate spheroid with vertical rotating axis (PV), and sphere (Sp). The horizontally $(\mathrm{OH}$ and $\mathrm{PH}$ ) and vertically (OV and $\mathrm{PV}$ ) oriented particles were present in proportions of $76 \%$ and $22 \%$, and oblate and prolate spheroids were in proportions of $76 \%$ and $24 \%$, respectively. The most common shape type was $\mathrm{OH}(57 \%)$.

The terminal velocities of $\mathrm{OH}, \mathrm{OV}, \mathrm{PH}, \mathrm{PV}$, and $\mathrm{Sp}$ were obtained analyzing 2-D video disdrometer data. The terminal velocities of PV were highest compared to those of other particle types. The lowest terminal velocities were found in $\mathrm{OH}$ particles. It is interesting that the terminal velocities for $\mathrm{OH}$ decreased rapidly in the range $0.5<D<1 \mathrm{~mm}$, corresponding to the decrease in axis ratio (i.e., smaller the particle, the flatter the shape). The axis ratios of all particle types except Sp were found to be converged to 0.94 at $D>2 \mathrm{~mm}$.

The histogram of canting angles followed unimodal and bimodal distributions with respect to horizontally and vertically oriented particles, respectively. The mean values and the standard deviation of entire particle shape types were
\end{abstract}

close to 0 and $10^{\circ}$, respectively, under calm atmospheric conditions.

\section{Introduction}

Volcanic eruptions are considered one of the most severe types of natural phenomena and can lead to human casualties and property damage. Ash consists of very fine-grained fragments, their volume-equivalent spherical particle diameter $(D$ in $\mathrm{mm})$ is generally smaller than $2 \mathrm{~mm}$, and they are generally dominated by broken glass shards rather than crystal and lithic fragments. Wilson et al. (2012) give an overview of the ash's effects on critical infrastructure, including from ash fall and acid rain. Hilman et al. (2012) investigate the effect ash particles have on human health in the case of Sakurajima's volcanic eruptions. More comprehensive descriptions of volcanic ash's impacts on society are found in Sigurdsson et al. (2015) and Wilson et al. (2015). Following an eruption, fine airborne volcanic ash flows for several tens of kilometers, which can cause major problems by increasing aviation traffic (e.g., Bonadonna et al., 2012; Langmann et al., 2012); this was seen after the eruption of Eyjafjallajökull volcano in Iceland during the period 14-21 April 2010; see, e.g., Bonadonna et al. (2011). From the viewpoint of volcanological hazard reduction, accurate description of transport and deposition in a numerical forecasting model of volcanic ash clouds is vitally important (Poulidis et al., 2017). 
Terminal fall velocity $\left(V_{\mathrm{T}}\right)$ of a particle is affected by its shape, density, size, and atmospheric properties. Wilson and Huang (1979), Dellino (2005), and Coltelli et al. (2008) introduced the influence of ash particle shapes on its $V_{\mathrm{T}}$. Haider and Levenspile (1989) and Ganser (1993) analyzed $V_{\mathrm{T}}$ of volcanic ash particles on the drag coefficient $\left(C_{\mathrm{D}}\right)$, which is dependent on particle shape and atmospheric condition. Transport and sedimentation of volcanic ash are complex processes, and the residence time and fall velocity of ash is critically dependent on particle size (Bonadonna et al., 1998), where, with respect to the latter, smaller particles could be flowing in the atmosphere further from the vent.

Aerodynamic properties are important for safe aviation and for studying the effects of volcanic ash on climate change, since these parameters determine the residence time of ash particles in the atmosphere (e.g., Folch et al., 2009). The $V_{\mathrm{T}}$ of particles varies widely due to their irregular shapes and material components (e.g., Wilson, 1972; Harris and Rose, 1983; Bonadonna et al., 2011; Maki et al., 2016). Bonadonna et al. (2011) analyzed $V_{\mathrm{T}}$ of volcanic ash particles with various particle densities $\left(\rho_{\mathrm{S}}\right)$ from 990 to $2738 \mathrm{~kg} \mathrm{~m}^{-3}$, and Maki et al. (2016) summarized the list of various $V_{\mathrm{T}}$ relationships suggested by previous studies. Volcanic ash particles have a range of shapes, and this presents a major challenge when analyzing their characteristics. Recently, the irregularity of volcanic ash particles was analyzed in detail based on the features of various regular particles, such as cubes, cylinders, and disks (Bagheri and Bonadonna, 2016), using a computed tomography (CT) scanner (Dioguardi et al., 2017; Garboczi and Bullard, 2017).

There are two approaches to studying these aerodynamic properties. The first approach is theoretical, where a numerical simulation model is used to calculate terminal velocities, drag force, and Reynolds number $(R e)$; examples of this approach can be found in Happel and Brenner (2012). The second approach is related to experimental research, in which the aforementioned relationships are determined experimentally. For instance, Bagheri et al. (2013) and Bagheri and Bonadonna (2016) analyzed the aerodynamic features of irregularly shaped ash particles from the free-fall experiments. Dioguardi et al. (2018) suggested a new model of fluid drag for irregularly shaped particles using previous research. Since the aerodynamic feature depends on atmospheric condition and it can affect the retrieval of $V_{\mathrm{T}}$, it could be suggested that it can be analyzed through the free-fall laboratory experiments for the following main reasons: (1) there is little chance to measure natural falling ash particles, (2) it could be possible to control the size of ash particle in the free-fall experiments, (3) and it could reduce the wind effect in the experiments.

The present study applies the second approach (experimental research) to clarify the physical characteristics of volcanic ash particles analyzing the experimental data. The rest of this paper is organized as follows. Section 2 describes the free-fall experiments of ash particles and methods of analy- sis, Sect. 3 presents the results of the free-fall experiments, Sect. 4 is discussion, and Sect. 5 summarizes the results.

\section{Data and methods}

\subsection{Two-dimensional (2-D) video disdrometer}

The 2-D video disdrometer (2DVD) was developed by Joanneum Research (Graz, Austria) to detect single raindrop particles, and the instrument has been modified to cover the errors caused by turbulence effects (Nešpor et al., 2000). The device is able to observe the shape, $V_{\mathrm{T}}$, and $\beta$ of a single particle using optical light. The ability to analyze a single particle is a significant advantage compared to other disdrometers, such as the Joss-Waldvogel disdrometer (Joss and Waldvogel, 1967), the Precipitation Occurrence Sensor System (Sheppard, 1990), and Parsivel (Löffler-Mang and Joss, 2000). For instance, Parsivel considers a fixed measurement area without any consideration of particle shape (e.g., Tokay et al., 2014), while 2DVD observes particles by passing them through a $100 \mathrm{~cm}^{2}$ observation area consisting of two light sources, i.e., reflecting mirrors and two cameras, with one camera set $6.2 \mathrm{~mm}$ above the other and collecting data with a resolution of 630 pixels; this results in a pixel size of $0.2 \mathrm{~mm}$ at $55 \mathrm{kHz}$ (Kruger and Krajewski, 2002). Particles passing through the observation area yield shape information according to the radiation intensity of the light sources, which is helpful for calculation of $\gamma$ and $\beta$. The $V_{\mathrm{T}}$ of particles is calculated using the height difference between the two cameras. Based on these advantages, the oscillation and particle shape of raindrops can be analyzed by 2DVD (Thurai and Bringi, 2005). Böhm (1989) analyzed the aerodynamic properties of an irregular hydrometeor and Huang et al. $(2010,2015)$ used 2DVD to analyze the features of irregularly shaped snow. There have been few previous aerodynamic analyses of volcanic ash particles performed using 2DVD, which is able to detect and analyze volcanic ash particles with a range of irregular shapes. Thus, 2DVD offers a unique approach as a new observation strategy.

\subsection{Definition of particle shape type}

Volcanic ash particles have various shapes that can be detected by 2DVD (Fig. 1). In the case of raindrops, the drop size distribution (DSD) is dependent upon the breakup and coalescence processes occurring via up and downdrafts, since the forces of gravity and buoyancy can easily affect raindrop shapes (Rosenfeld and Ulbrich, 2003). However, solid particles do not readily change shape when falling without the influence of forces such as collision. It is thus inferred that many particle shapes would be found in the atmosphere, and that it would be possible to define and classify each particle shape type if we were able to accurately detect a single particle. Thus, the range of $\gamma$ for solid particles would be expected to be wide compared to that of raindrops, and 


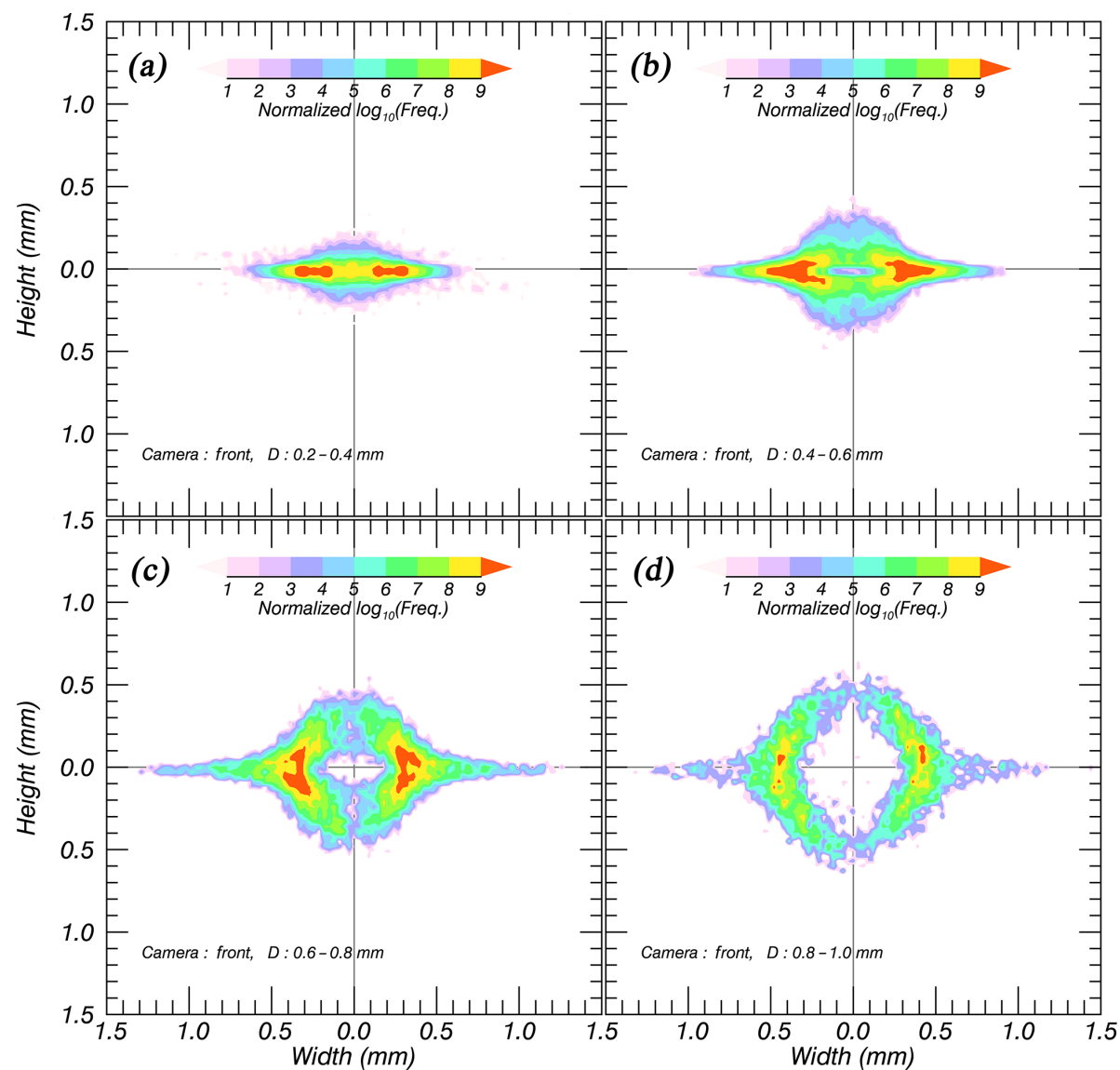

Figure 1. Accumulated contoured images of volcanic ash particles, with $D$ measured by a two-dimensional video disdrometer (2DVD).

various values of $V_{\mathrm{T}}$ and $\beta$ would likely be observed. The $\gamma_{x}$ of a particle is defined as the ratio of height to width for the observation direction $x$, and its representative value is calculated using the geometric means of the two $\gamma\left(\gamma_{1}, \gamma_{2}\right)$ detected by cameras 1 and 2, respectively (Eq. 1):

$\gamma_{1(2)}=\frac{\operatorname{Height}_{1(2)}}{\operatorname{Width}_{1(2)}}, \quad \gamma=\sqrt{\gamma_{1} \gamma_{2}}$.

The difference in angle between the rotating symmetric axis and vertical axis is defined as $\beta$. The counter-clockwise (clockwise) movement of the rotating symmetric axis has a positive (negative) value and the entire range is $180^{\circ}$ (from -90 to $90^{\circ}$ ) with $0^{\circ}$ as the center.

It is necessary to consider the true axis ratio $\left(\gamma_{\mathrm{T}}\right)$ to correctly define the particle shape (Fig. 2). The apparent axis ratio $\left(\gamma_{\mathrm{A}}\right)$ considers the effect of $\beta$ but the $\gamma_{\mathrm{T}}$ does not. The 2-D coordinates $(x, z)$ of the particle shape with $\beta$ are defined as follows:

$x_{\mathrm{A}}=r \cos (\theta+\beta), \quad z_{\mathrm{A}}=r \sin (\theta+\beta)$,

$x_{\mathrm{T}}=r \cos \theta, \quad z_{\mathrm{T}}=r \sin \theta$,

where subscript A is the coordinate of the original data coordinate considering the $\beta$ and subscript $\mathrm{T}$ is the modified data

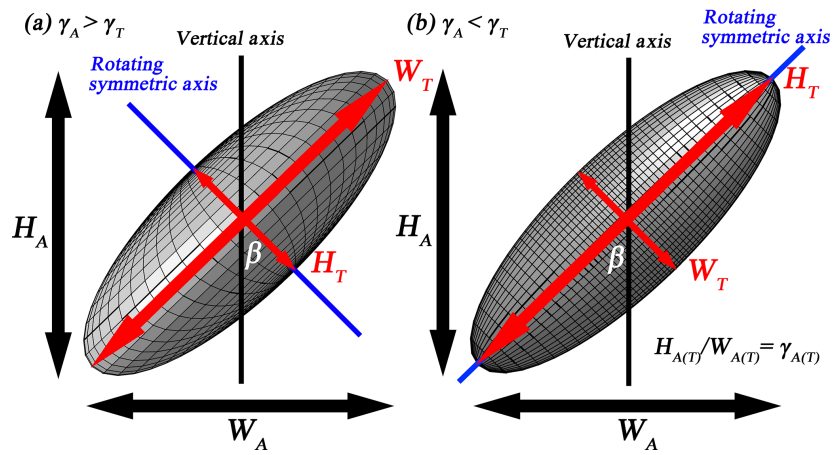

Figure 2. Conceptual model of an (a) oblate and (b) prolate spheroid with the same canting angle $(\beta) . W_{\mathrm{A}(\mathrm{T})}$ and $H_{\mathrm{A}(\mathrm{T})}$ are the apparent (true) width and height of the particle, respectively. $\gamma_{\mathrm{A}}(\mathrm{T})$ is the apparent (true) axis ratio.

coordinate. The symbol $r$ refers to the length from the data point to the center and the symbol $\theta$ represents the degrees of data coordinates from the positive $x$ axis, which range between 0 and $180^{\circ}$. In this paper, $\gamma$ stands for $\gamma_{\mathrm{A}}$ for convenience. 
An objective criterion for particle shape type was considered since particle shapes can be highly diverse and irregular (e.g., Bagheri and Bonadonna, 2016; Dioguardi et al., 2017, 2018; Garboczi and Bullard, 2017). In the case of irregular particles, the $\gamma$ can change according to the observation direction; however, any criterion should be able to define the particle shape types strictly and reliably. To solve this problem, particles with a rotating symmetric axis were the main target of the present study. Therefore, we considered oblate spheroid $(\mathrm{O})$, prolate spheroid $(\mathrm{P})$, and sphere $(\mathrm{Sp})$, which all have a rotating symmetric axes. Among these particle types, the major axes of the oblate and prolate spheroids could be horizontally $(\mathrm{H})$ and vertically $(\mathrm{V})$ oriented with respect to the ground, respectively. Thus, the various particle shapes were divided into five types as follows; oblate spheroid with horizontal rotating axis $(\mathrm{OH})$, oblate spheroid with vertical axis $(\mathrm{OV})$, prolate spheroid with horizontal rotating axis $(\mathrm{PH})$, prolate spheroid with vertical rotating axis (PV), and Sp.

To define these particle shape types, a strict definition of the $\gamma_{T}$ is required, which can be calculated from the $\beta$. As with the $\gamma$, the two $\beta$ values are automatically calculated by 2DVD. In the case where the $\beta$ is assumed to be $0^{\circ}$, the rotating symmetric axis for $\mathrm{OH}$ and $\mathrm{PV}$ can be defined, since it is observed for any observation direction parallel to the ground. However, in the case of $\mathrm{OV}$ and $\mathrm{PH}$ particles, the rotating symmetric axis cannot be defined when the observation direction is parallel. In the case where the $\beta$ is not $0^{\circ}$, $\gamma_{\mathrm{T}}$ for all particle shape types would not change when oscillation occurs in a direction orthogonal to the observation direction, but it is difficult to estimate both $\gamma_{\mathrm{T}}$ and $\beta$ when particle oscillation appears in a direction parallel to the observation direction. The ability to restore the $\gamma_{\mathrm{T}}$ and $\beta$ relative to this observation direction is limited, which is one of the main disadvantages of the 2-D observation strategy.

Based on these facts, a major $\beta$ was selected based on the following reasoning: (i) a $\beta$ for the observation direction with lower (higher) $\gamma_{\mathrm{T}}$ for $\mathrm{OH}(\mathrm{PV})$ is selected. (ii) In the case of $\mathrm{OV}(\mathrm{PH})$, for which the rotating symmetric axis was observed for only one observation direction, $\beta$ was considered where the value of $\beta$ had a higher (lower) $\gamma_{\mathrm{T}}$ than that of the other observation direction. Therefore, $\beta$ with a lower (higher) $\gamma_{\mathrm{T}}$ in two observation directions for the case of an oblate (prolate) particle was considered a meaningful value. The perfect sphere could not have their value of $\beta$ determined theoretically because there is the possibility of a rotating symmetric axis in any direction.

Based on the definition of $\beta$ (Fig. 2), the perfect condition with respect to ellipsoids is satisfied when $|\beta|=0^{\circ}\left(90^{\circ}\right)$ for $\mathrm{OH}$ and $\mathrm{PV}(\mathrm{OV}$ and $\mathrm{PH})$; these values are defined as the center values. However, 2DVD calculated that the $\beta$ for each particle shape type was concentrated around $|\beta|=0^{\circ}\left(90^{\circ}\right)$ with respect to horizontally (vertically) oriented particles, which correspond to $\mathrm{OH}$ and $\mathrm{PH}(\mathrm{OV}$ and $\mathrm{PV}$ ). Furthermore, analysis of particles with an orthogonal center angle from $0^{\circ}$ is dif-
Table 1. Ash particle classification criteria.

\begin{tabular}{lll}
\hline Type & Description & $\begin{array}{l}\text { Classification } \\
\text { conditions }\end{array}$ \\
\hline OH & Horizontal oblate & $\begin{array}{l}\gamma_{\mathrm{T}_{1(2)}}<0.9 \\
\left|\gamma_{\mathrm{T}_{1}}-\gamma_{\mathrm{T}_{2}}\right| \leq \gamma_{\mathrm{T}}\end{array}$ \\
\hline OV & Vertical oblate & $0.9 \leq \gamma_{\mathrm{T}_{1(2)}} \leq 1.1$, \\
& & $\gamma_{\mathrm{T}_{2(1)}}>1.1$ \\
\hline PH & Horizontal prolate & $\left|\gamma_{\mathrm{T}_{1}}-\gamma_{\mathrm{T}_{2}}\right|>0.1 \gamma_{\mathrm{T}}$ \\
\hline PV & Vertical prolate & $\gamma_{\mathrm{T}_{1(2)}}>1.1$ \\
& & $\left|\gamma_{\mathrm{T}_{1}}-\gamma_{\mathrm{T}_{2}}\right| \leq \gamma_{\mathrm{T}}$ \\
\hline $\mathrm{Sp}$ & Sphere & $0.9 \leq \gamma_{\mathrm{T}_{1(2)}} \leq 1.1$ \\
& & $\left|\gamma_{\mathrm{T}_{1}}-\gamma_{\mathrm{T}_{2}}\right| \leq \gamma_{\mathrm{T}}$ \\
\hline
\end{tabular}

ficult, since they have two center angles $\left( \pm 90^{\circ}\right)$. To address observation errors and enhance the convenience of analysis, all center angles were set to $|\beta|=0^{\circ}$ and modified to give the representative canting angle, $\beta_{\mathrm{R}}$, using the following equation:

$\beta_{\mathrm{R}}=\beta-\beta_{0}$,

where $\beta_{0}$ is the orienting angle, defined by the central angle of oscillation. In the case of vertically oriented particles (OV and PV), $\beta_{0}$ could be defined as $\pm 90^{\circ}$. The sign of $\beta_{0}$ follows that of $\beta$.

After removing $\beta$, each particle shape was defined using $\gamma_{\mathrm{T}}$ (Table 1). Note that a $10 \%$ bias range was allowed, to take observational error into account. For example, a particle was considered a sphere when $0.9<\gamma_{\mathrm{T}}<1.1$, which is an applied $10 \%$ bias range from $\gamma_{\mathrm{T}}=1$. In addition, the particle types $\mathrm{OH}$ and $\mathrm{PV}(\mathrm{OV}$ and $\mathrm{PH})$ were classified when the value of $\left|\gamma_{1}-\gamma_{2}\right|$ was smaller (larger) than $0.1 \gamma_{\mathrm{T}}$, to consider particles with only a rotating symmetric axis.

\subsection{Calculate the terminal velocity for the various particle shape types}

The $V_{\mathrm{T}}$ of volcanic ash is required to estimate the $R_{\mathrm{A}}$ $\left(\mathrm{kg} \mathrm{m}^{-2} \mathrm{~s}^{-1}\right)$ on the ground where this depends on atmospheric density $\left(\rho_{g}\right.$ in $\left.\mathrm{g} \mathrm{cm}^{-3}\right), T, R e, C_{\mathrm{D}}, D, \rho_{\mathrm{s}}$, and its shape. Kunii and Levenspiel (1969) developed a theoretical $V_{\mathrm{T}}$ equation:

$V_{\mathrm{T}}=\left(\frac{4\left(\rho_{\mathrm{s}}-\rho_{g}\right) g D}{3 \rho_{g} C_{\mathrm{D}}}\right)^{0.5}\left(10^{0}<R e<10^{4}\right)$.

Later, Suzuki (1983) developed a theoretical $V_{\mathrm{T}}$ equation for tephra. Bonadonna et al. (2011) then modified the theoretical $V_{\mathrm{T}}$ equation suggested by Kunii and Levenspiel (1969) with observed ash data, which implied that the result of the theoretical $V_{\mathrm{T}}$ equation could be unsuitable for nonspherical particles. Based on these equations, various $C_{\mathrm{D}}$ equations 
considering nonspherical particles were subsequently developed. Tran-Cong et al. (2004) developed a new equation for $C_{\mathrm{D}}$ using the function of circularity, and Hölzer and Sommerfeld (2008) introduced a progressed $C_{\mathrm{D}}$ equation considering two types of sphericity: lengthwise $\left(\Phi_{\|}\right)$and crosswise $\left(\Phi_{\perp}\right)$. This equation is as follows:

$$
\begin{aligned}
& C_{\mathrm{D}}=\frac{8}{\operatorname{Re}} \frac{1}{\sqrt{\Phi_{\|}}}+\frac{16}{\operatorname{Re}} \frac{1}{\sqrt{\Phi}}+\frac{3}{\sqrt{\operatorname{Re}}} \frac{1}{\Phi^{3 / 4}} \\
& +0.42 \times 10^{0.41(-\log (\Phi))^{0.2}} \frac{1}{\Phi_{\perp}} .
\end{aligned}
$$

The $R e$ is defined as follows:

$$
R e=\frac{\rho_{g} V_{\mathrm{T}} \mathrm{D}}{\mu},
$$

where $\mu$ is the dynamic viscosity $\left(\mathrm{kg} \mathrm{m}^{-1} \mathrm{~s}^{-1}\right)$, which we assumed to be $1.983 \times 10^{-5}$ based on atmospheric conditions at a $T$ of $25^{\circ} \mathrm{C}$. Three types of sphericity were defined as follows:

$\Phi=\frac{\pi D^{2}}{\mathrm{SA}}$,

where SA is the surface area of the particle $\left(\mathrm{mm}^{2}\right)$. The lengthwise sphericity is defined as the ratio between the cross-sectional area of the volume-equivalent sphere and the difference between half the surface area and the mean of the projected vertical cross-sectional area $\left(A_{\mathrm{V}}\right)$ of the particle (Eq. 6):

$\Phi_{\|}=\frac{\pi D^{2}}{4\left(0.5 \times \mathrm{SA}-A_{\mathrm{V}}\right)}$.

The crosswise sphericity is the same as the lengthwise sphericity, except for the denominator, which includes the projected horizontal cross-sectional area of the particle $\left(A_{\mathrm{H}}\right)$, defined as follows:

$\Phi_{\perp}=\frac{\pi D^{2}}{4 A_{\mathrm{H}}}$.

It is noteworthy that the $V_{\mathrm{T}}$ is required to calculate the $R e$ and $V_{\mathrm{T}}$, which refers to the final product. To solve this problem, the theoretical $V_{\mathrm{T}}$ (Eq. 2) was used as the input value of Eq. (4) until Eq. (2) converged.

\subsection{Sakurajima}

Japan has around $10 \%$ (110) of all of the active volcanos in the world. Sakurajima (1117 m.a.s. $1,31.58^{\circ} \mathrm{N}, 130.65^{\circ} \mathrm{E}$, Kyushu, Japan) is an active volcanic island formed around $13000 \mathrm{yr}$ ago, and its tephra is approximately $60 \%-66 \%$ $S_{i} \mathrm{O}_{2}$ Peléan type (Oguchi et al., 2009; Takahashi et al., 2013). The major eruptive events in the historic age of Sakurajima were 1471-1476 (Bunmei era), 1779-1782 (An'ei

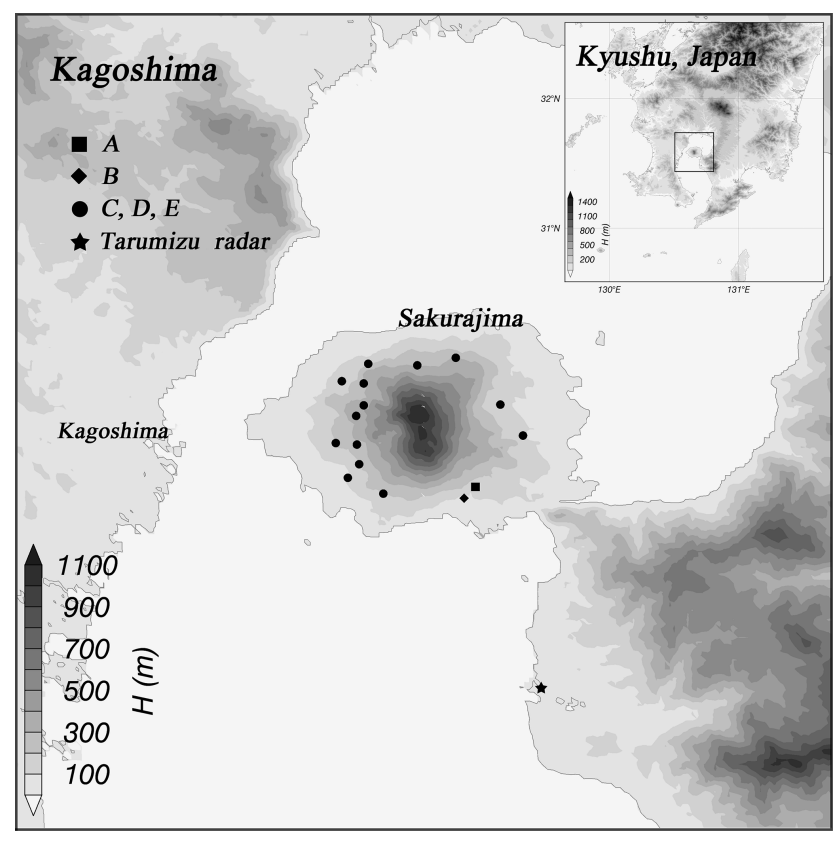

Figure 3. The locations of tephrometers and Showa crater on Sakurajima, Japan. Black symbols indicate the locations of tephrometers, and the star, square, and circle symbols correspond to data sets A, $\mathrm{B}$ and $\mathrm{C}-\mathrm{E}$, respectively. The white circle symbol represents the location of Showa crater.

era), and 1914 (Taishō era). Sakurajima is an andesitic volcano with two peaks (Kita-dake and Minami-dake). Volcanic activity at Kita-dake ended around $4900 \mathrm{yr}$ ago when it changed to Minami-dake. Activity has centered on Showa crater from 2006 (Iguchi, 2013). Showa crater is located on the eastern flank, approximately $500 \mathrm{~m}$ east of Minami-dake (southern peak) on Sakurajima. It was appeared in 1939 after 1 month of eruptions (Yokoo and Ishihara, 2007). The Minami-dake summit crater was the only active center of Sakurajima until the recommencement of Showa crater from 1948 to 2006. The eruptive activity of Showa crater resumed in June 2006, and vulcanian eruptions gradually increased in the autumn of 2009 (Hotta et al., 2016). The Japan Meteorological Agency (JMA) reported that the eruption frequency of Sakurajima would increase significantly from 2009, and the accumulated ash fall exceeded $3.5 \mathrm{~kg} \mathrm{~m}^{-2}$ in Kagoshima in 2012. The Ministry of Land, Infrastructure, Transport, and Tourism (MLITT) installed an operational X-band radar $10.7 \mathrm{~km}$ from the vent, as well as 16 automatic volcanic ash weight measurements, to observe volcanic eruptions in 2011 (Fig. 3).

\subsection{Free-fall experiments}

The data were collected by automatic volcanic ash weight measurements performed on Sakurajima (Tajima et al., 2015; Maki et al., 2014, 2016). The free-fall experiments were divided into two types: one was performed for each phi scale 
Table 2. Information on the collected volcanic ash particles.

\begin{tabular}{llll}
\hline Data & Collection date & $\begin{array}{l}\text { Period of free fall } \\
\text { experiment (18 June 2014) }\end{array}$ & Condition of free fall \\
\hline A & 1-31 December 2008 & $10: 00-12: 34(154 \mathrm{~min})$ & Size by size (phi scale) \\
B & 1-31 March 2010 & $13: 43-14: 53(70 \mathrm{~min})$ & Size by size (phi scale) \\
C & 28 February 2014 & $15: 11-16: 17(66 \mathrm{~min})$ & Mixed \\
D & 31 March 2014 & $16: 19-17: 05(46 \mathrm{~min})$ & Mixed \\
E & 30 April 2014 & $17: 07-18: 00(53 \mathrm{~min})$ & Mixed \\
\hline
\end{tabular}

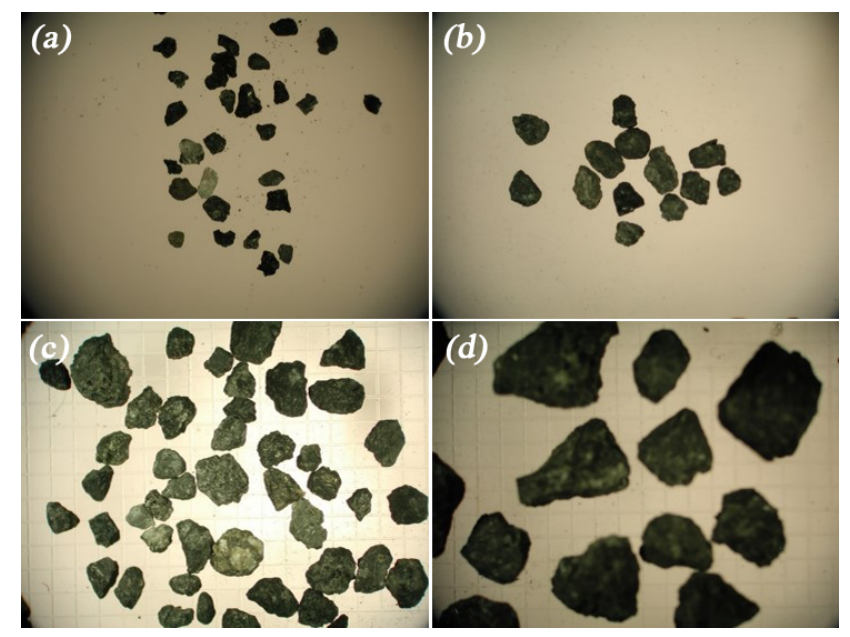

Figure 4. Real images of volcanic ash particles used in the present study. The particles were classified as (a) $0.125 \mathrm{~mm} D \leq 0.25 \mathrm{~mm}$, (b) $0.25 \mathrm{~mm} D \leq 1 \mathrm{~mm}$, (c) $1 \mathrm{~mm} D<2 \mathrm{~mm}$, and (d) $2<D \leq$ $4 \mathrm{~mm}$.

$\left(\Phi=-\log _{2} D\right)$ from $\Phi=3$ to $-4(0.125<D<16 \mathrm{~mm})$ and the other was not considered on a particle-size scale. The former data, expressed by A and B (Type 1), were collected at two sites and screened by size (Fig. 4); the latter data, expressed as C-E (Type 2), were collected at 18 sites (Table 2). Free-fall experiments on collected volcanic ash particles were carried out in the large-scale rainfall simulator of the National Research Institute for Earth Science and Disaster Prevention (NIED) in Tsukuba, Japan. The collected particles were dropped manually around $17 \mathrm{~m}$ from the ground and re-collected by a third-generation 2DVD (Maki et al., 2016). Each sample was dropped for 30 s to stimulate dispersion, and the measurement period was $1 \mathrm{~min}$. To avoid wind effects including turbulence, the 2DVD was surrounded by a $3 \mathrm{~m}^{3}$ wind-breaking wall (Fig. 5).

The free-fall experiments were conducted at intervals of 1 min over $6.5 \mathrm{~h}$, as shown in Fig. 6. The number of particles detected by 2DVD was less than 10000 for $1 \mathrm{~min}$, and the particle size range of the Type 1 data set was proportional to its phi scale, since small particles may be contained by screening.

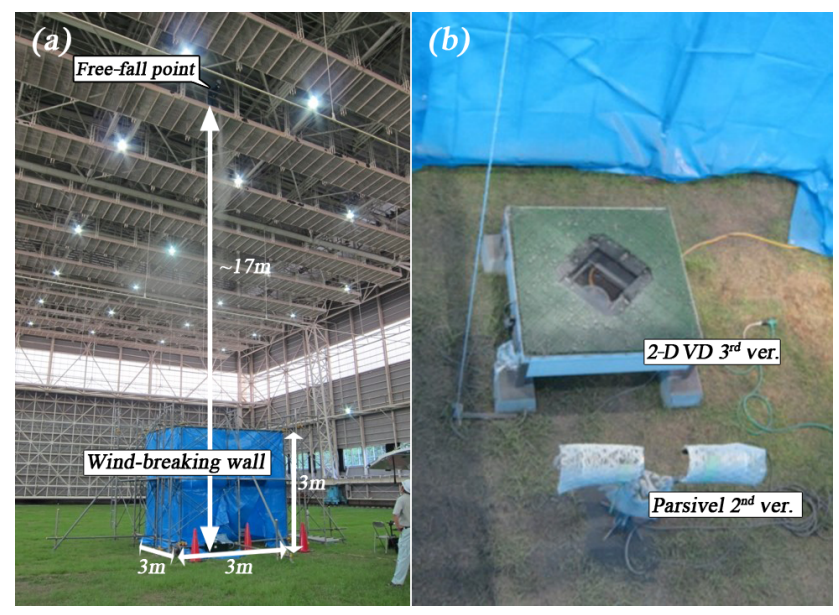

Figure 5. Free-fall experiment conditions of volcanic ash particles on the (a) outside and (b) inside of the wind-breaking wall covering the disdrometers in the large-scale rainfall simulator of the National Research Institute for Earth Science and Disaster Prevention (NIED).

Figure 7 shows the distribution of raw data (the number of data: 274215) for $V_{\mathrm{T}}$ and $\gamma$ with $D$. There were various $\gamma$ from 0 to 2 when $D<2 \mathrm{~mm}$, and most of the data were concentrated near $\gamma=0$. The $\gamma$ values converged around 1 and their distributional range decreased with $D$. The median value with a $0.25 \mathrm{~mm} D$ interval corresponded well to the center of the data contour. The median line converged around $\gamma=0.935$ based on the correlation coefficient value (CC). When this was higher than 0.95 for each $D$ interval, the data converged. According to this condition, the range of $2<D<5 \mathrm{~mm}$ was satisfied and the mean value was calculated using these data. The $V_{\mathrm{T}}$ had a wider range when $D<$ $2 \mathrm{~mm}$ but the median line corresponded well to the center of the data (Fig. 7b). The line representing the largest number of data is lower than the volcanic ash discussed by Bonadonna et al. (2011). To select a available range of $D$, a theoretical terminal velocity equation $\left(V_{\mathrm{T}, \mathrm{Ref}}\right)$ for a non-sphere corresponding to Eqs. (2)-(7) was used as the reference. The particle density associated with the eruption of Sakurajima is between 2.43 and $2.59 \mathrm{~g} \mathrm{~cm}^{-3}$ (Oguchi et al., 2009), but the actual particles contain air vacuoles (Van Eaton et al., 2012). This means that $\rho_{\mathrm{s}}$ including vacuoles is smaller than 


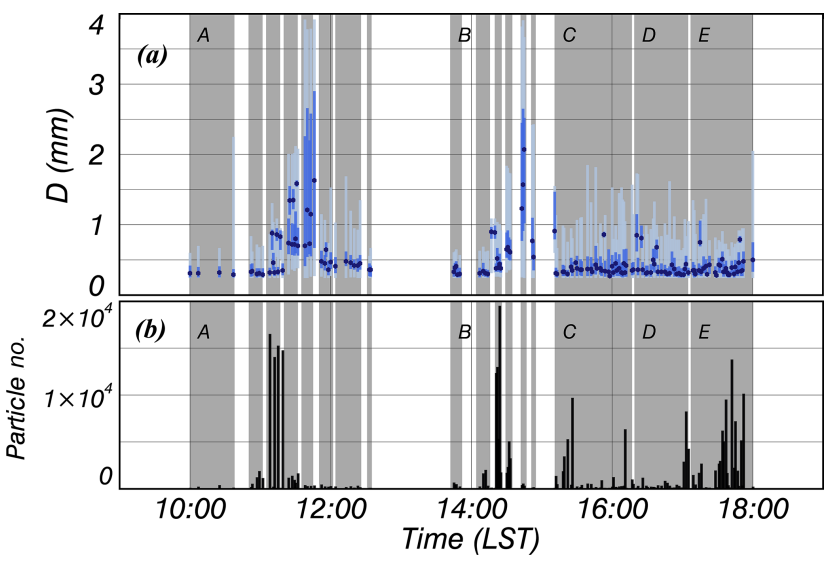

Figure 6. The $1 \mathrm{~min}$ interval time series of $D$ and the number of particles in the free-fall experiment conducted at the NIED.

$\rho_{\mathrm{S}}$ alone. Therefore, the minimum $\rho_{\mathrm{S}}$ was considered to be $2.43 \mathrm{~g} \mathrm{~cm}^{-3}$, and this was used as an input parameter. The atmospheric conditions of $T$ and $P$ were considered from an automatic weather station (AWS), supported by the JMA. The falling height of a particle, which followed the aforementioned conditions $\left(\gamma=0.935, \rho_{\mathrm{s}}=2.43 \mathrm{~g} \mathrm{~cm}^{-3}\right)$ when $D=4$ was lower than that under the condition of the free-fall experiment $(17 \mathrm{~m})$ and it reached $90 \%$ of $V_{\mathrm{T}}(13.9 \mathrm{~m})$; therefore, the available data range is considered to be $D \leq 4 \mathrm{~mm}$, and this would satisfy the terminal fall velocity. The detailed equations used in the present study are shown in Appendix A.

\subsection{Quality control procedures}

The 2DVD was originally developed to detect raindrop hydrometeors. For this reason, additional quality control (QC) checks were deemed necessary to ensure applicability to nonhydrometeors, such as volcanic ash particles. Specifically, we performed the following three QC procedures for accurate analysis of the data.

i. Particle $D>0.25 \mathrm{~mm}$ was selected in consideration of the minimum spatial resolution of 2DVD.

ii. If the major axis observed by 2DVD was $10 \%$ longer than that of the value calculated directly based on data coordinates, the data were considered erroneous and thus removed. A $10 \%$ bias range was considered due to mathematical error, the irregular particle shape, and the limitation of the spatiotemporal resolution of 2DVD.

iii. To consider volcanic ash particles, the sample that satisfied the criteria in the chosen range of the terminal velocity relationship was selected. If we consider a single $V_{\mathrm{T}} \mathrm{QC}$ measurements for the entire particle shape type, a number of available data will be removed, since $V_{\mathrm{T}}$ critically depends on particle shape. Therefore, we applied a $60 \% V_{\mathrm{T}} \mathrm{QC}$ threshold (Jaffrain et al., 2011) for
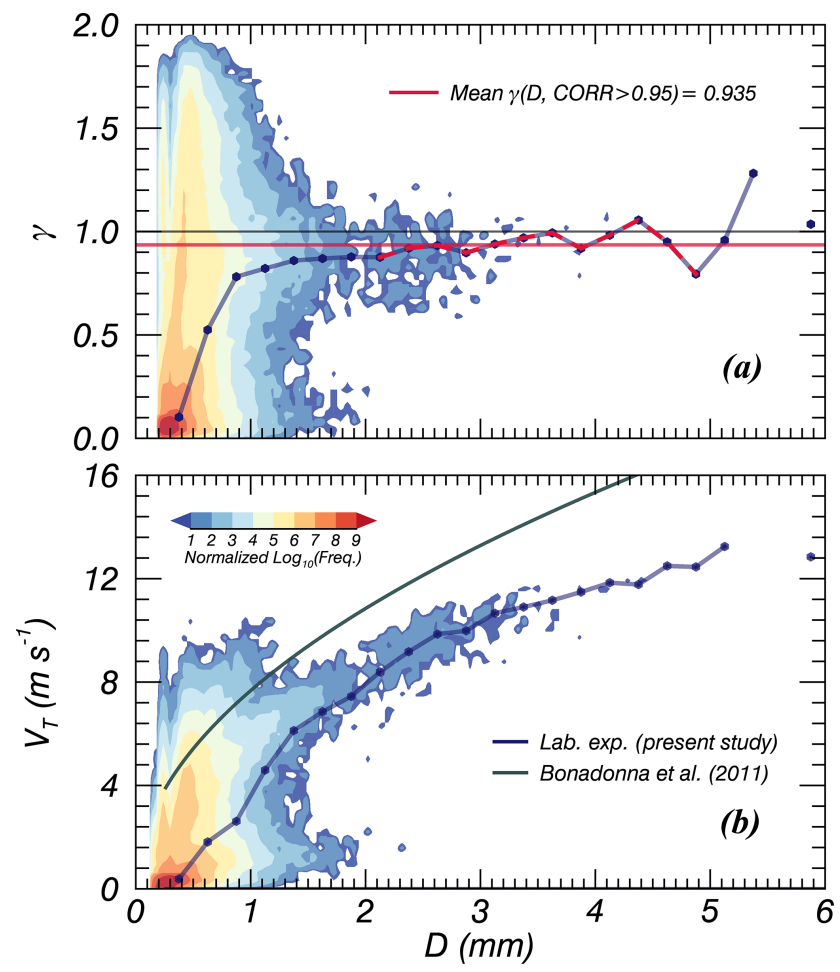

Figure 7. Contour image of volcanic ash particles for (a) the axis ratio $(\gamma)$ and (b) terminal velocity $\left(V_{\mathrm{T}}\right)$. The solid red line is the averaged $\gamma$ satisfying the condition that the correlation coefficient exceeds 0.95 . The solid grey line is the relationship of volcanic ash particles suggested by Bonadonna et al. (2011).

each particle shape type. It could be applied once the $V_{\mathrm{T}}$ relationship of volcanic ash particles is obtained. After selecting the particle shape types and applying these two QC procedures (i and ii), $19.31 \%$ of the data (62953) remained (Table 1).

\section{Results}

\subsection{Ash particle shape}

The ash particle size over the entire volcanic ash sample was skewed leftward, and the dominant particle shape type changed with particle size (Fig. 8). The particles were predominantly horizontally oriented $(75.51 \%)$ and vertically oriented $(21.60 \%)$. Oblate and prolate spheroids made up $76.26 \%$ and $23.85 \%$ of the particles, respectively. Hence, the particles were mainly $\mathrm{OH}(57.38 \%)$ or $\mathrm{PH}(15.88 \%)$ (Table 2). The particles were predominantly $0.25<D<$ $0.5 \mathrm{~mm}(63.00 \%)$ or $0.5<D<1 \mathrm{~mm}(32.80 \%)$. Relatively few particles had $D>1 \mathrm{~mm}(4.20 \%)$.

There was large variation in shape among particles $0.25<$ $D<0.5 \mathrm{~mm}$, but the variation decreased with increasing $D$. All of the particle shape types had the largest number of particle at $D>1.0 \mathrm{~mm}$ and the next largest were shown 


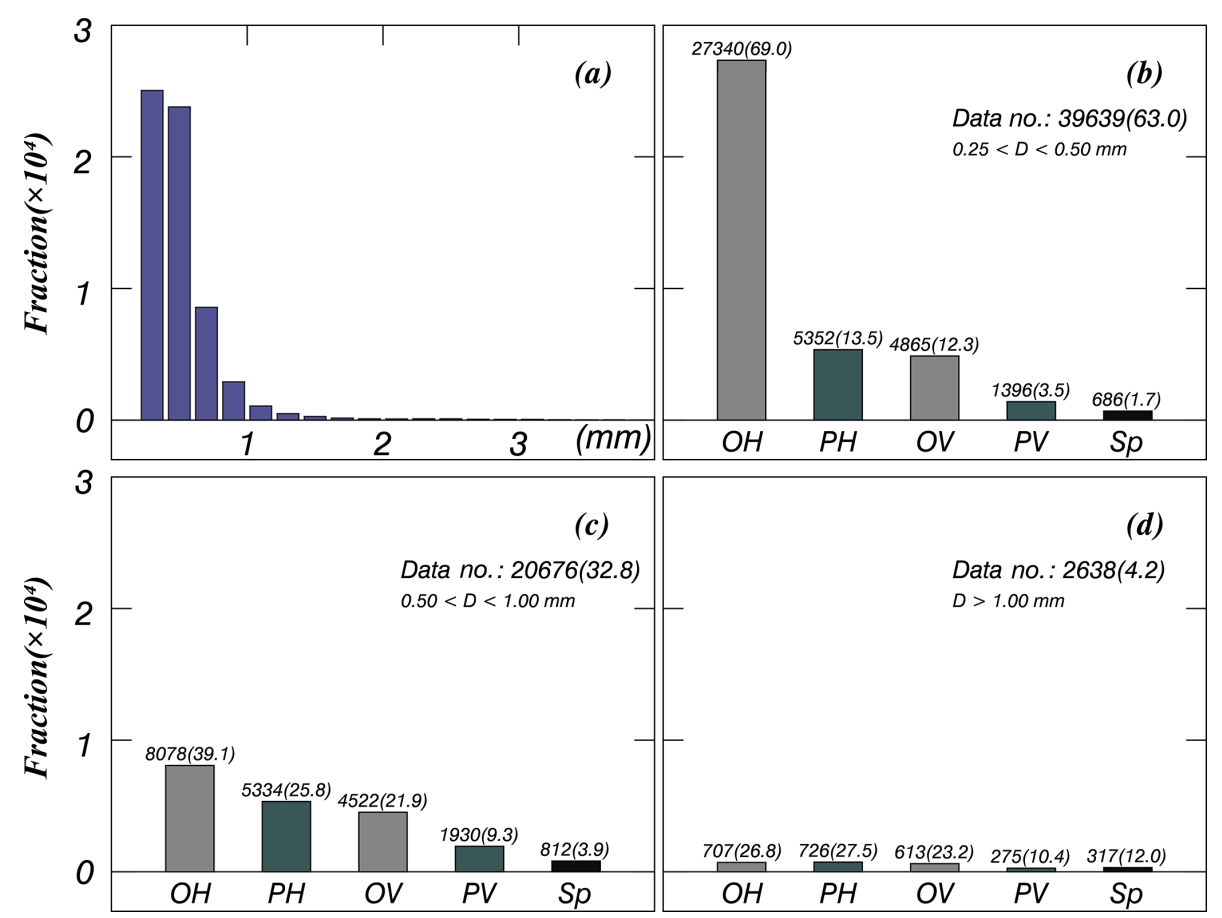

Figure 8. Histograms of volcanic ash particles for (a) all particle types and (b-d) each particle shape type of the phi scale. The grey-shaded and dark-grey-shaded (patterned) bars indicate horizontal oblate $(\mathrm{OH})$ (vertical oblate, $\mathrm{OV}$ ) and horizontal prolate (PH) (vertical prolate, $\mathrm{PV}$ ), respectively. The black bar corresponds to spherical (Sp) particles. The number on the top of each bar plot is the number of data points, and the number in parentheses is the percentage for each phi scale.

at $0.5<D<1.0 \mathrm{~mm}$, except for $\mathrm{OH}$. In total, $95.80 \%$ of OH particles had $D<1 \mathrm{~mm}$, at $D<0.5 \mathrm{~mm}$ the value was $75.68 \%$, and at $D=0.5-1 \mathrm{~mm}$ it was $22.36 \%$. In the cases of $\mathrm{PH}$ and $\mathrm{OV}, 93.63 \%$ and $93.87 \%$ of these particles, respectively, had $D<1 \mathrm{~mm}$. Beyond $D>1 \mathrm{~mm}$, the differences in the number of particles for each particle shape type were considerably decreased.

\subsection{Terminal velocity}

The $V_{\mathrm{T}}$ for the entire particle shape types follows a polynomial regression analysis that was applied to define the nonlinear relationship between $V_{\mathrm{T}}$ and $D$ (Fig. 9a). It corresponds to that obtained by Miwa et al. (2015), who analyzed Parsivel data using the same laboratory experiments. The inflection point of $V_{\mathrm{T}}$ was at $D<1.3 \mathrm{~mm}$ and it came from an increase in the number of $\mathrm{OH}$ and a decrease in their $V_{\mathrm{T}}$ when $D<1 \mathrm{~mm}$. As a result, the $V_{\mathrm{T}}$ relationship for each particle shape type can be seen clearly.

The observed values of $V_{\mathrm{T}}$ were well classified by particle shapes (Fig. 9b). The highest values of $V_{\mathrm{T}}$ were recorded in the following order: prolate, sphere, and oblate. Vertically oriented particles had higher $V_{\mathrm{T}}$ values than horizontal ones. The $V_{\mathrm{T}}$ for every particle type can be expressed in a power law form, except for $\mathrm{OH}$. $\mathrm{OH}$ particles followed the regression line relatively closely and showed the highest $\mathrm{CC}$ and root-mean-square error (RMSE) values of 0.94 and
$0.46 \mathrm{~m} \mathrm{~s}^{-1}$, respectively. Horizontally oriented particles had relatively high correlations $(\mathrm{OH}: 0.94$; $\mathrm{PH}: 0.87)$ compared to those with a vertical orientation (OV: 0.75 ; PV: 0.71$)$. The $V_{\mathrm{T}}$ relationships and those of statistical parameters are summarized in Table 3.

To verify the reliability of the particle data obtained by 2DVD, which was originally developed to detect liquid raindrops, $\rho_{\mathrm{s}}, C_{\mathrm{D}}$, and $R e$, as well as theoretical $V_{\mathrm{T}}$ values according to these parameters, were analyzed. To calculate the parameters of interest, including the surface area and crosssectional area of irregular particles, we applied the irregular particle volume estimation equations of Huang et al. (2010).

\subsection{Aerodynamic properties}

Particle densities were estimated using the $V_{\mathrm{T}, \text { Ref }}$, converged to $2.37 \mathrm{~g} \mathrm{~cm}^{-3}$ when $D<1.5 \mathrm{~mm}$ (Fig. 10a). This value corresponds well to that of the minimum $\rho_{\mathrm{s}}\left(2.43 \mathrm{~g} \mathrm{~cm}^{-3}\right)$ reported by Oguchi et al. (2009). The slight difference is likely due to observation errors and the presence of vesicles (e.g., Seligman et al., 2016). The median value of $\rho_{\mathrm{s}}$ is changed to $0.5<D<1.5 \mathrm{~mm}$, and this range corresponds to that of $V_{\mathrm{T}}$. Horizontally oriented particles $(\mathrm{OH}$ and $\mathrm{PH})$ have relatively smaller $\rho_{\mathrm{S}}$ and vertically oriented particles (OV and PV) have higher density (Fig. 10b); spheres have particle densities that accord best with $D$. The median $\rho_{\text {s }}$ values for all particle 
Table 3. Relationships of terminal velocity, with the number of data points, the value of the correlation coefficient (CC), and the root-meansquare error (RMSE), after applying the $60 \% V_{\mathrm{T}} \mathrm{QC}$ threshold for each particle shape type.

\begin{tabular}{|c|c|c|c|c|}
\hline Type & Data number $(\%)$ & Relationship $(0.25<D(\mathrm{~mm}) \leq 4)$ & $\mathrm{CC}$ & RMSE \\
\hline All & $32685(100)$ & $V_{\mathrm{T}}(D)=0.15 D^{3}-1.51 D^{2}+6.69 D$ & 0.56 & 1.22 \\
\hline \multirow[t]{2}{*}{$\mathrm{OH}$} & $10757(33)$ & $\begin{array}{l}V_{\mathrm{T}}(D)=0.14 \exp (2.40 D)(0.25 \leq D< \\
1.6) \\
V_{\mathrm{T}}(D)=4.77 D^{0.67}(1.6 \leq D<4)\end{array}$ & 0.94 & 0.46 \\
\hline & & $V_{\mathrm{T}}(D)=5.96 D^{0.53}$ & 0.75 & 0.85 \\
\hline PH & $8619(26)$ & $V_{\mathrm{T}}(D)=5.09 D^{0.65}$ & 0.87 & 0.74 \\
\hline PV & $3170(10)$ & $V_{\mathrm{T}}(D)=6.47 D^{0.49}$ & 0.71 & 0.96 \\
\hline $\mathrm{Sp}$ & $1444(4)$ & $V_{\mathrm{T}}(D)=5.61 D^{0.56}$ & 0.91 & 0.78 \\
\hline
\end{tabular}

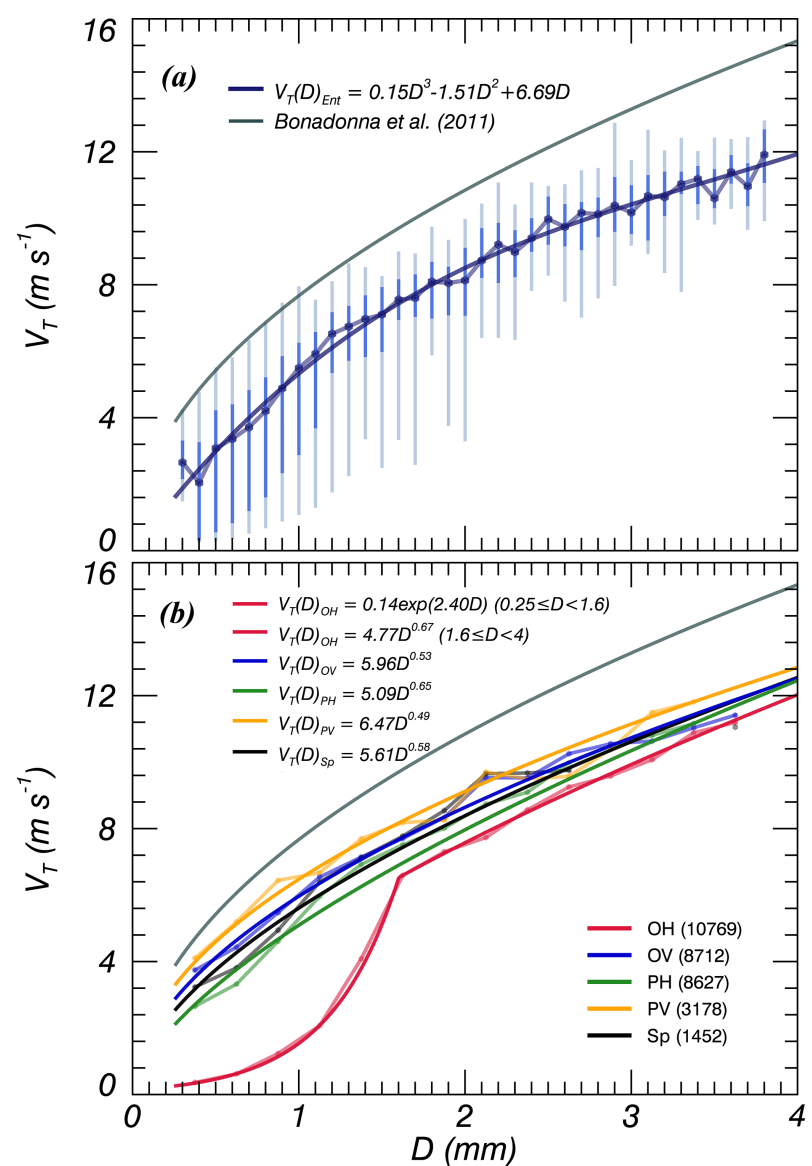

Figure 9. Distribution of (a) quartile and (b) median terminal velocity $\left(V_{\mathrm{T}}\right)$ values after applying the $60 \% V_{\mathrm{T}}$ QC threshold for all shape types and each individual particle shape type, respectively. The solid grey line shows the relationships of the volcanic ash particles suggested by Bonadonna et al. (2011).

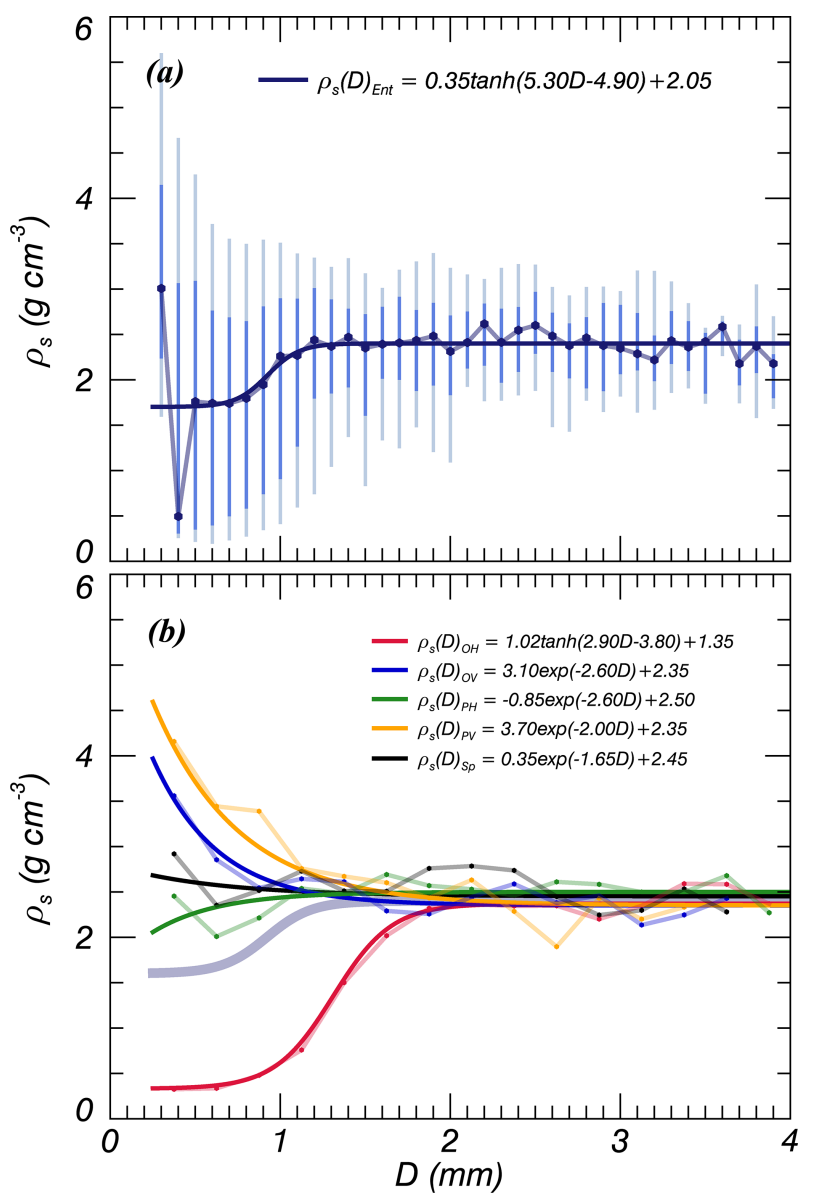

Figure 10. Same as Fig. 9 but for particle density $\left(\rho_{\mathrm{S}}\right)$. 


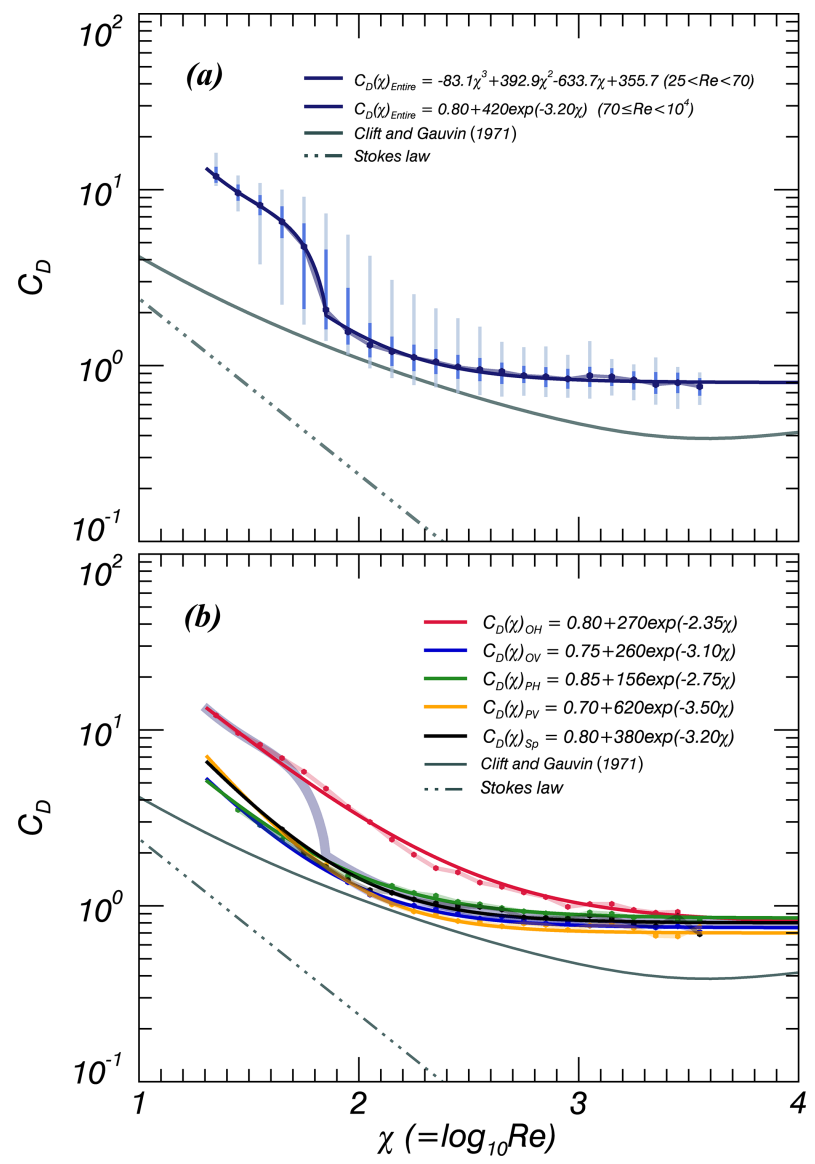

Figure 11. Same as Fig. 9 but for Reynolds number $(R e)$ and drag coefficient $\left(C_{\mathrm{D}}\right)$. The solid grey and broken grey lines in (a) are the relationships of spheres suggested by Clift and Gauvin (1971) and Stokes (1851), respectively.

shapes converged when $D<2 \mathrm{~mm}$, and the converged $\rho_{\mathrm{s}}$ values ranged from 2.35 to $2.50 \mathrm{~g} \mathrm{~cm}^{-3}$.

The $R e$ and $C_{\mathrm{D}}$ for the all particle shapes ranged from 10 to 4000 and 0.6 to 20 , respectively (Fig. 11a). Higher values of $C_{\mathrm{D}}$ were observed when $\log (R e)<1.845(R e<70)$; above this threshold, $C_{\mathrm{D}}$ dramatically decreased. These results were derived according to the number of $\mathrm{OH}$ particles, which mainly had $D<0.5 \mathrm{~mm}$ and had higher $C_{\mathrm{D}}$ and lower $R e$. Particle shape was divided into two types: $\mathrm{OH}$ and others (Fig. 11b). OH particles had higher $C_{\mathrm{D}}$ compared to the other particle shapes, which in turn showed few differences among themselves. The $\mathrm{OH}$ particles experience strong drag forces under the same flow conditions, leading to lower $V_{\mathrm{T}}$. The differences between $\mathrm{OH}$ and other particles diminished with $R e<1000$. The other particle shapes had relatively higher $C_{\mathrm{D}}$ in the range $10<R e<3000$. Rong et al. (2015) analyzed the relationship between $R e$ and $C_{\mathrm{D}}$ for oblate and prolate particles and showed that $\mathrm{OH}$ particles had higher $C_{\mathrm{D}}$ compared to the reference line (Clift and Gauven, 1971) in

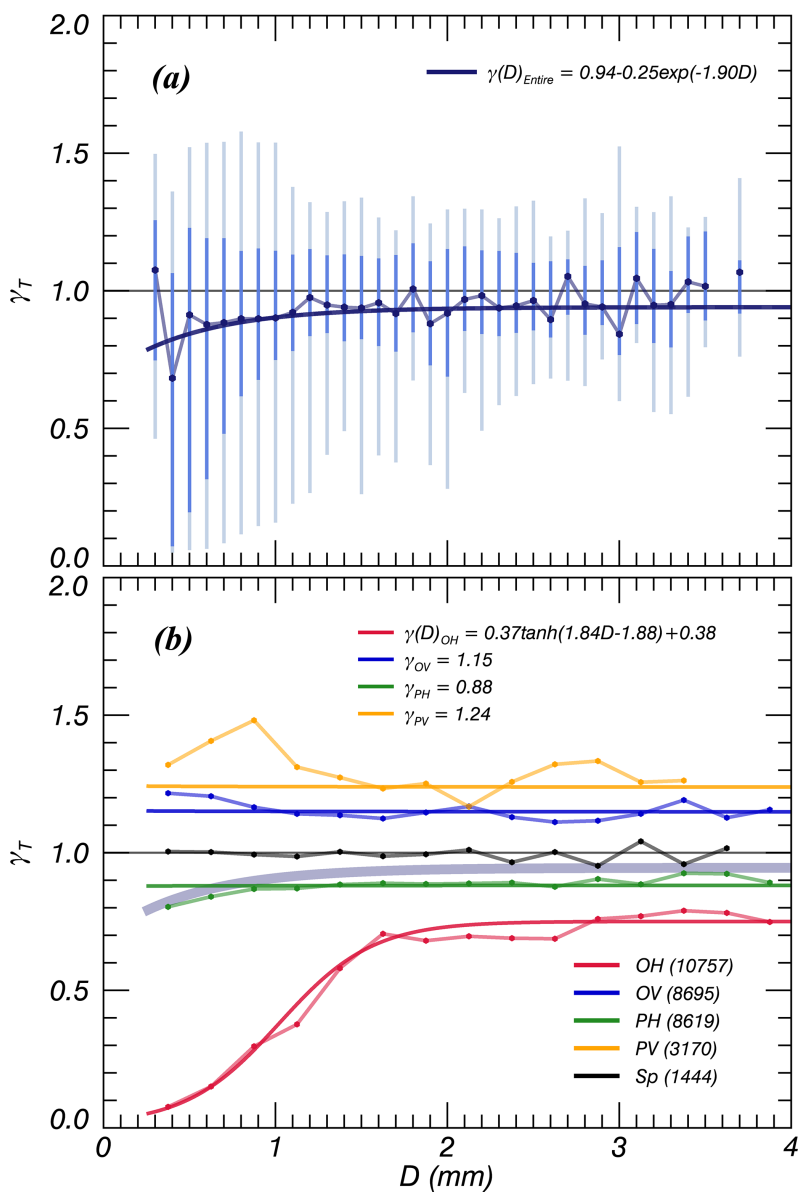

Figure 12. Same as Fig. 9 but for $\gamma$.

the range $0<R e<400$. Each relationship is summarized in Fig. 11.

\subsection{Axis ratio}

The $\gamma$ of a particle affects the backscattering power of electromagnetic waves and is necessary to calculate the horizontal reflectivity $\left(Z\right.$ in dBZ), differential reflectivity $\left(Z_{\mathrm{DR}}\right.$ in $\mathrm{dB})$, and specific differential phase shift $\left(K_{\mathrm{DP}}\right.$ in $\left.{ }^{\circ} \mathrm{km}^{-1}\right)$. Note that previous studies have analyzed the $\gamma$ distribution for raindrops and snow, including hail; however, few studies have been reported on $\gamma$ of ash particles compared to those for hydrometeors.

Figure 12 shows the quartiles and median values of $\gamma$ for all particle shapes and for each individual particle shape type. The $\gamma$ had a higher standard deviation $\left(\sigma_{\gamma}\right)$ of $>0.25$ when $D<0.75 \mathrm{~mm}$, which decreased and converged to $\sigma_{\gamma}=0.15$ when $D>1 \mathrm{~mm}$ (Fig. 12a). The $\gamma$ in the lower $\sigma_{\gamma}$ range converged to $\gamma=0.94$ and could be expressed as follows:

$\gamma(D)=0.94-0.25 \exp (-1.90 D)$.

The particles are more easily classified by shape than by $V_{\mathrm{T}}$ (Fig. 12b). Every particle shape type was independent of 


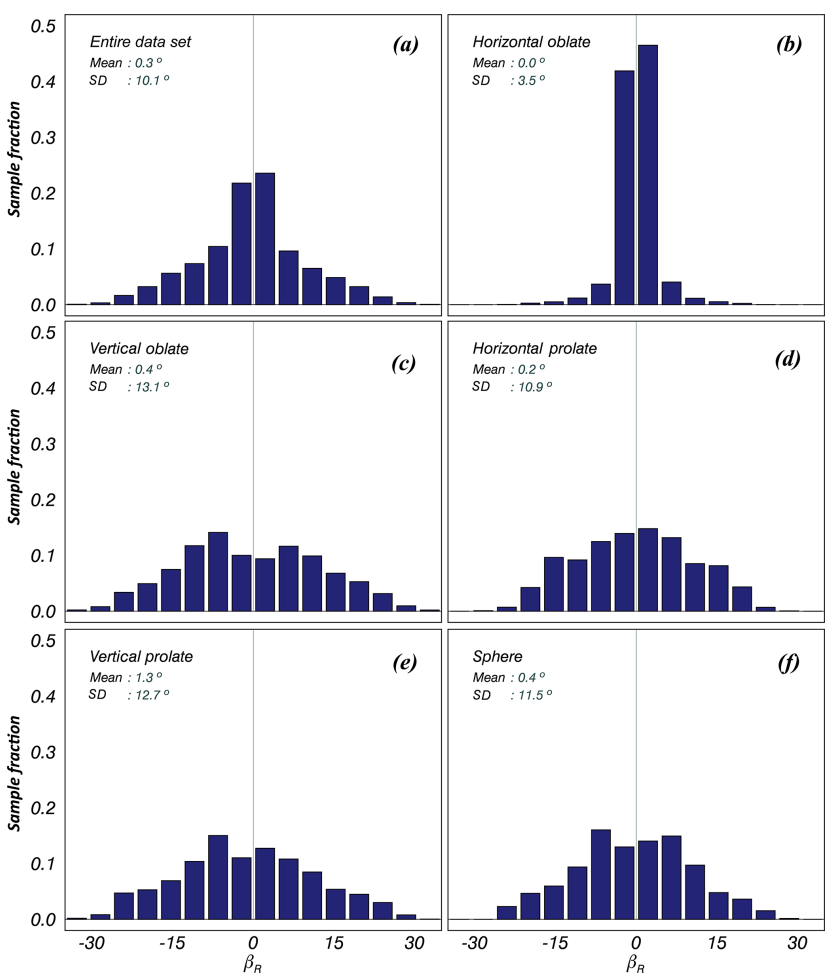

Figure 13. Histograms of representative canting angle $\left(\beta_{\mathrm{R}}\right)$ for each particle shape type, including the data for all particles.

$D$, except for $\mathrm{OH}$. The $\gamma$ of each particle type is expressed via the following relationships (Eqs. 9-12).

$\gamma(D)_{\mathrm{OH}}=0.37 \tanh (1.84 D-1.88)+0.38$

$\gamma_{\mathrm{OV}}=1.15$

$\gamma_{\mathrm{PH}}=0.88$

$\gamma_{\mathrm{PV}}=1.24$

The parameter $\gamma(D)_{\mathrm{OH}}$ was calculated using the hyperbolic tangent (tanh) for the following reasons: (i) its range of values was wider than those of other particle types, (ii) its data distribution changed continuously with $D$, and (iii) it was present in a higher proportion $(30.44 \%)$ compared to the other parameters. We found that variations in $\gamma$ decreased with $D$ and the proportion of Sp shapes increased when $D>2 \mathrm{~mm}$. The particle types $\mathrm{OV}$ and $\mathrm{PH}$ showed a wide distribution over $1<\gamma<1.5$ and $0.4<\gamma<1.0$, respectively, when $D<2 \mathrm{~mm}$, but the variability in median values was relatively low. The relationships of $\gamma$ for each particle shape type could be expressed by constant values at $\gamma=0.75(\mathrm{OH})$, $0.88(\mathrm{PH}), 1.15(\mathrm{OV})$, and $1.24(\mathrm{PV})$, respectively, and these differences are around $\gamma=0.12$.

\subsection{Canting angle}

Statistical analysis of $\beta$ is required to understand the aerodynamic properties of volcanic ash particles and the input

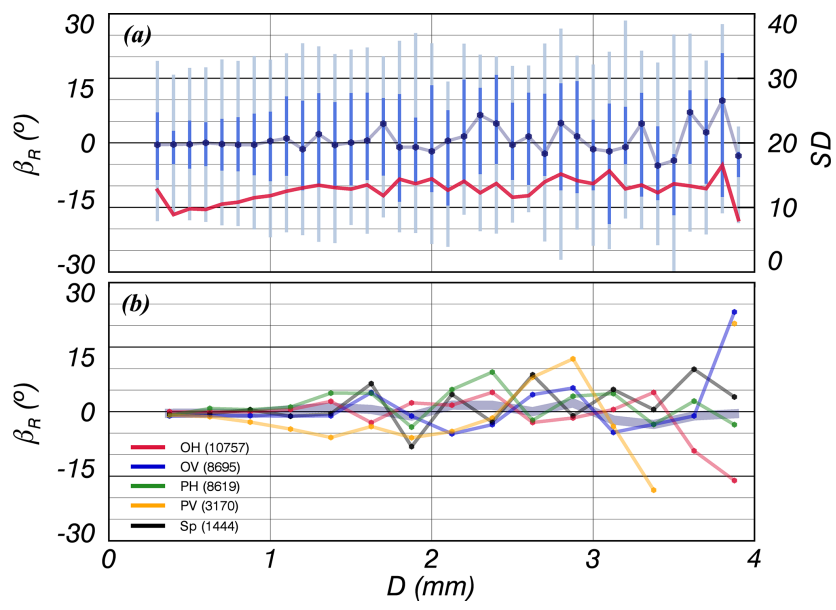

Figure 14. Distribution of $\beta_{\mathrm{R}}$ with $D$ for each particle shape type including the data for all particles. The solid red line indicates the standard deviation.

parameters of T-matrix scattering simulations to verify the observed radar variables. The histogram of $\beta_{\mathrm{R}}$ is shown in Fig. 13.

More than $95 \%$ of $\beta$ values for each particle shape type were concentrated in the range $\left|\beta_{\mathrm{R}}\right| \leq 30^{\circ}$, with $0^{\circ}$ as the center (Fig. 13). The particles were symmetrically distributed around $0^{\circ}$ and more than $50 \%$ were concentrated in the range $\left|\beta_{\mathrm{R}}\right|<4^{\circ}$. The horizontally oriented $\beta$ distribution was relatively narrow $\left(\left|\beta_{\mathrm{R}}\right|<20^{\circ}\right)$ and exhibited a unimodal distribution. It is noteworthy that $90 \%$ of $\mathrm{OH}$ particles were concentrated in the range $\left|\beta_{\mathrm{R}}\right|<4^{\circ}$. The vertically oriented $\beta$ distribution was relatively broad $\left(\left|\beta_{\mathrm{R}}\right|<30^{\circ}\right)$ and followed a bimodal distribution. PV exhibited a bimodal form, but this was not symmetrical around $0^{\circ}$. For spheres, the $\beta$ distribution was narrower, similar to horizontally oriented particles, and it had a bimodal distribution, similar to vertically oriented particles, indicating that the independent features of both orientations were combined.

The values of $\left|\overline{\beta_{\mathrm{R}}}\right|$ and $\left|\sigma_{\beta}\right|$ for $\mathrm{OH}$ and $\mathrm{PV}(\mathrm{OV}, \mathrm{PH})$ were 0 and $3.5^{\circ}\left(0.4,13.1^{\circ}\right)$ and 1.3 and $12.7^{\circ}\left(0.2,10.9^{\circ}\right)$, respectively. OV $(\mathrm{OH})$ had the highest (lowest) value of $\left|\sigma_{\beta}\right|$. This validates the assumption of Marzano et al. (2012) under stable conditions $\left(\left|\sigma_{\beta}\right|=10^{\circ}\right)$. Therefore, we believe that the tumbling phenomenon $\left(\left|\sigma_{\beta}\right|>30^{\circ}\right)$ of the particles under calm atmospheric conditions was likely to be minor.

To analyze the correlation between particle $D$ and $\beta$, quartiles for each particle $D$ interval were calculated (Fig. 14). The particles were concentrated at $\left|\beta_{\mathrm{R}}\right|<30^{\circ}$ regardless of $D$, and median values were stable when $D<1 \mathrm{~mm}$ for the entire particle shape types; however, fluctuation increased with $D$ (Fig. 14a). The $\left|\sigma_{\beta}\right|$ values gradually increased from 10 to $13^{\circ}$ when $0.3<D<1.3 \mathrm{~mm}$, and variability was greatest around the center $\left(13^{\circ}\right)$. This increase in $\left|\sigma_{\beta}\right|$ would not be expected in the case of a relatively small number of particles 
(Fig. 8a), since their standard deviation is largely maintained at about $13^{\circ}$ regardless of data set size.

Variability in the median values for individual particles was more apparent. The values converged around $0^{\circ}$ but fluctuation increased with greater $D$ from the zero line. The median $\left|\beta_{\mathrm{R}}\right|$ values exceeded $3,5,10$, and $15^{\circ}$ when $D>1 \mathrm{~mm}$, $1<D<2 \mathrm{~mm}, 2<D<3 \mathrm{~mm}$, and $D>3 \mathrm{~mm}$, respectively (Fig. 14b).

\section{Discussions}

The results of present study can be extended in viewpoint of the radar meteorology: (i) the radar observation and (ii) ashfall rate $\left(R_{\mathrm{A}}\right)$ estimations. Weather radar operates for a similar purpose to that of meteorological satellites, and provides information for determining the volume, mass, and echo top height of weather systems. Short-duration eruptions, i.e., less than $1 \mathrm{~h}$, can be detected at high spatiotemporal resolution, especially in the early period of an eruption. The temporal resolution of weather radar is a few minutes for a single volume scan and depends on the observation strategy and radar band. The spatial resolution of weather radar is a few hundred meters and is proportional to the radar frequency. A number of ash cloud detections were reported in several observational cases in the US and Japan (Maki and Doviak, 2001; Maki et al., 2012). Marzano et al. (2013) summarized 28 major explosive volcanic eruptions detected by weather radars from 1970 to 2011. Harris and Rose (1983) attempted to analyze volcanic ash particle size and total mass using a C-band weather radar. Maki and Doviak (2001) proposed the method to retrieve particle size distribution (PSD) from radar measurements of volcanic ash, and Donnadieu et al. (2012) detected volcanic eruptions using an L-band fixed radar. Marzano et al. (2006, 2012) and Maki et al. (2012, 2014) detected and analyzed volcanic eruptions using weather radars from theoretical (physical) and experimental (engineering) perspectives, respectively. Thus, observability of volcanic ash clouds using weather radar can be confirmed from previous researches. To verify radar-based volcanic ash cloud observations, a scattering simulation can be considered. The basic parameters, axis ratio and canting angle, are the results presented in this study and the input information of scattering simulations used to simulate the theoretical radar variables. In particular, the T-matrix scattering simulation developed by Waterman (1971) is useful for calculation of the theoretical backscattering power of nonspherical particles.

Second, $V_{\mathrm{T}}$ is one of the main parameters for $R_{\mathrm{A}}$ $\left(\mathrm{kg} \mathrm{m}^{-2} \mathrm{~h}^{-1}\right)$ and is defined in terms of PSD and $V_{\mathrm{T}}$ as follows:

$$
R_{\mathrm{A}}=V_{r} \frac{3.6}{10^{3}} \int_{D_{1}}^{D_{2}} V_{\mathrm{T}}(D) N(D) D^{3} \mathrm{~d} D,
$$

where $V_{r}$ is the particle volume ratio. In case of sphere, it is considered $\pi / 6$.

Marzano et al. (2012b) proposed $Z-C_{\mathrm{A}}$ relationships using the ash-fall concentration $\left(C_{\mathrm{A}}\right.$ in $\left.\mathrm{g} \mathrm{m}^{-3}\right)$ and $z$. Maki et al. (2016) introduced $R_{\mathrm{A}}-z$ relationship for Sakurajima eruption case (18 August 2013) using the time integration of $R_{\mathrm{A}}$ $\left(S_{\mathrm{A}}\right.$ in $\mathrm{kg} \mathrm{m}^{-2}$ ) obtained by automatic volcanic ash weight measurements. However, once we use a disdrometer, such as 2DVD, it will be possible to estimate $R_{\mathrm{A}}$ directly since 2DVD can measure PSD, $V_{\mathrm{T}}$, and $\gamma$. Therefore, basic parameters could help to simulate radar variables and estimate $R_{\mathrm{A}}$, which are necessary to develop the quantitative ash-fall estimation (QAE) method.

\section{Summary and conclusions}

The basic parameters $\left(V_{\mathrm{T}}, \gamma\right.$, and $\left.\beta\right)$ of volcanic ash particles were analyzed from the free-fall experiments with 2DVD. Data were collected with 18 automatic volcanic ash weight measurements performed on Sakurajima, Japan $\left(31.58^{\circ} \mathrm{N}\right.$, $\left.130.65^{\circ} \mathrm{E}\right)$. To identify the aerodynamic properties of the volcanic ash particles in the samples, a free-fall experiment was conducted in the large-scale rainfall simulator of the NIED, and 274215 samples were analyzed.

Radar variables are highly dependent on the $|K|^{2}$, size, and shape of particles. Particle types with rotating symmetric axes were assumed to represent volcanic ash particles that have a wide variety of irregular shapes. Their orientation was also considered with respect to horizontally $(\mathrm{OH}, \mathrm{PH})$ and vertically $(\mathrm{OV}, \mathrm{PV})$ oriented oblate and prolate spheroids.

The dominant particle shapes were comprised of horizontally and vertical oriented particles and present in proportions of $75.51 \%$ and $21.60 \%$, respectively. Regarding particle shape, oblate (prolate) spheroids comprised $76.26 \%$ $(23.85 \%)$ of all particles in the samples. The most common particle shape type was $\mathrm{OH}$, accounting for $59 \%$ of all particles when $D<1 \mathrm{~mm}$ and $69 \%$ when $D<0.5 \mathrm{~mm}$. Overall, $95.80 \%, 93.87 \%$, and $93.63 \%$ of the $\mathrm{OH}, \mathrm{OV}$, and $\mathrm{PH}$ particles had $D<1 \mathrm{~mm}$, respectively.

The $V_{\mathrm{T}}$ of the particles were classified in the following order: $\mathrm{PV}, \mathrm{OV}, \mathrm{Sp}, \mathrm{PH}$, and $\mathrm{OH}$. These results are consistent with the $V_{T, \text { Ref }}$, which suggests that 2DVD is reliable for observing volcanic ash particles under stable weather conditions. A noticeable increase in $V_{\mathrm{T}}$ for $\mathrm{OH}$ in the range $0.5<D<1 \mathrm{~mm}$ occurred through an increase in $\gamma$; this was not observed for other particle types.

The estimated $\rho_{\mathrm{s}}$ converged to $2.37 \mathrm{~g} \mathrm{~cm}^{-3}$ when $D>$ $1.5 \mathrm{~mm}$, and the median value changed over the range $0.5<$ $D<1.5 \mathrm{~mm}$. The converged value of $\rho_{\mathrm{s}}$ is consistent with the value for Sakurajima reported by Oguchi et al. (2009). The relationship of $C_{\mathrm{D}}$ and $R e$ were divided into two particle type categories $\left(\mathrm{OH}\right.$ and the others) and $C_{\mathrm{D}}(\mathrm{OH})$ was dramatically increased in the range of $R e<70$. These results were derived from the particle concentration of $\mathrm{OH}$, 
which was highest when $D<0.5 \mathrm{~mm}$; at this threshold, $C_{\mathrm{D}}$ was higher and $R e$ was lower. The range of $V_{\mathrm{T}}$ over $0.7<$ $D<1.3 \mathrm{~mm}$ was informed by both $\gamma$ and $\rho_{\mathrm{s}}$.

The $\sigma_{\gamma}$ decreased in the range of $D>0.75 \mathrm{~mm}$ to 0.15 and converged to $\gamma=0.94$. Maki et al. (2014) introduced the radar variables and found that $Z_{\mathrm{DR}}$ gradually increased with time; the dominant values at 10 and 18 min after the eruption were close to 1 and $2 \mathrm{~dB}$, respectively. The results presented in this study corresponded to volcanic eruption clouds with positive $Z_{\mathrm{DR}}$ since it is a function of $|K|^{2}$ and $\gamma$ (Herzegh and Jameson, 1992). In addition, it can be explained by using the results of present study, that the size sorting of ash particle (e.g., Beckett et al., 2015; Stevenson et al., 2015) will affect the increase in $Z_{\mathrm{DR}}$.

The $\left|\sigma_{\beta}\right|$ of OV particles with $\left|\beta_{0}\right|=90^{\circ}$ was largest $\left(13.1^{\circ}\right)$ among all particle types and $\mathrm{OH}$ particles had the lowest $\left|\sigma_{\beta}\right|$ at $3.5^{\circ}$. Based on the $\left|\sigma_{\beta}\right|$ results, the tumbling phenomenon would not be dominant under calm atmospheric conditions. The quartiles were stable when $D<1 \mathrm{~mm}$ for the entire particle shape types but increased with $D$. The value of $\sigma_{\beta}$ was higher when $D<1.3 \mathrm{~mm}$ and started to converge around $13^{\circ}$ due to a decrease in the number of $\mathrm{OH}$ particles.

These results could be the essential information to develop the new approaches for detecting non-hydrometeors and numerical model. The axis ratio and canting angle of ash particles obtained from the present study are necessary for scattering simulations. $V_{\mathrm{T}}$ obtained by the present study suggests that smaller particles can be transported over longer distances. Therefore, it will be useful for scattering simulation of ash particles to develop QAE and help to improve the numerical model using $V_{\mathrm{T}}$ obtained by the present study.

Data availability. The data obtained by 2DVD from the free-fall experiments are available on request from Masayuki Maki. 


\section{Appendix A: Appendix A}

The theoretical fall velocity and falling distance with time are calculated as follows:

$F=m a=F_{g}-F_{\mathrm{D}}$,

$F_{g}=m g$,

$F_{\mathrm{D}}=\frac{1}{2} \rho_{g} V^{2} C_{\mathrm{DA}}$,

where $F_{g}$ is universal gravitation, $F_{\mathrm{D}}$ is drag force, $m$ is mass, and $a$ is the free-fall acceleration. In Eq. (A2), $g$ is the acceleration due to gravity, considered to be $9.81 \mathrm{~m} \mathrm{~s}^{-2}$, and $V$ and $C_{\mathrm{D}}$ in Eq. (A3) correspond to the values in Eqs. (2)-(7). The symbols $\mu$ and $\rho_{g}$ are the dynamic viscosity and density of the atmosphere and were assumed to be $1.837 \times 10^{-5} \mathrm{~kg} \mathrm{~m}^{-1} \mathrm{~s}^{-1}$ and $1.194 \times 10^{-5} \mathrm{~g} \mathrm{~cm}^{-3}$, respectively. The results were based on conditions at an atmospheric $T$ as $25^{\circ} \mathrm{C}$.

To ensure accuracy, we considered the surface roughness effect of a volcanic ash particle $\left(1.07^{-1}\right)$ on the fall velocity, as suggested by Bagheri and Bonadonna (2016), and the results for $D=4 \mathrm{~mm}$ are shown in Fig. A1.
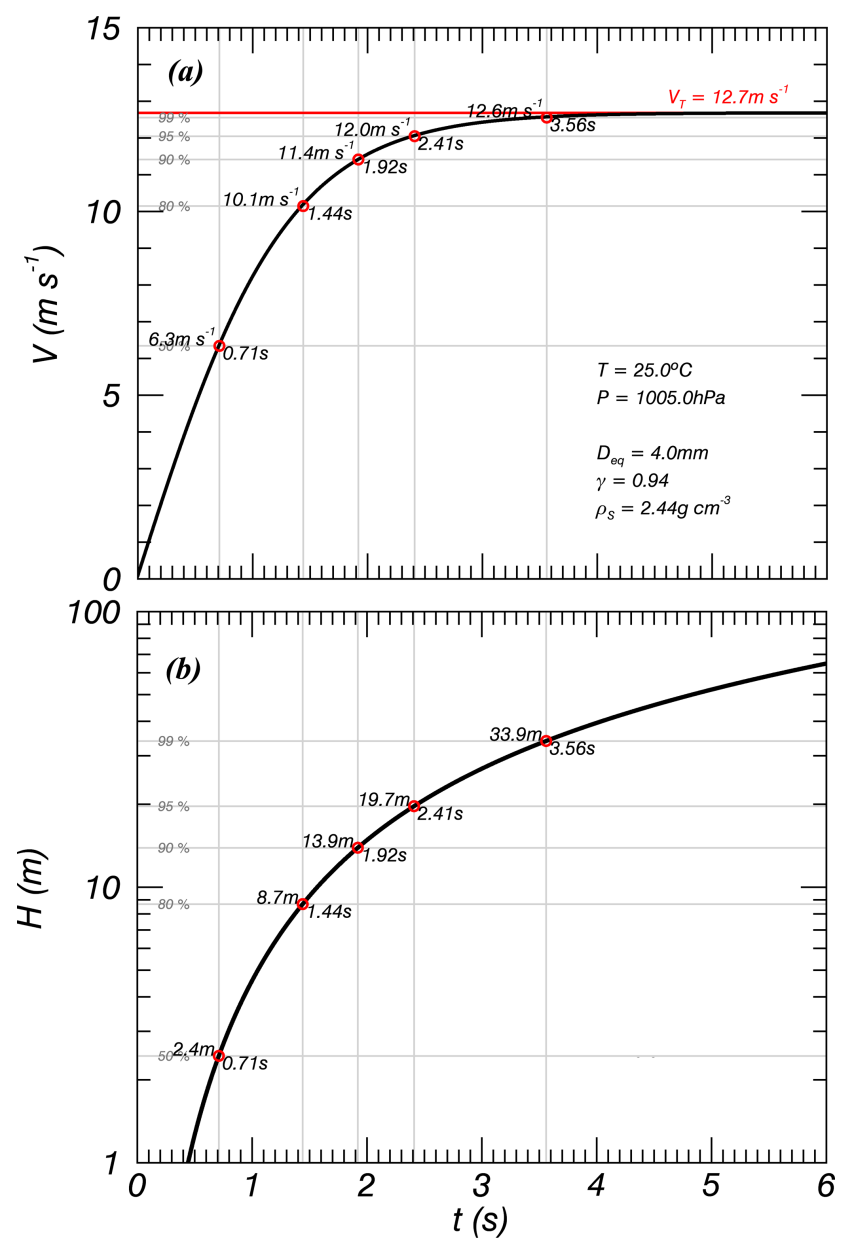

Figure A1. Theoretical (a) fall velocity and (b) falling height for a spheroid with $D=4 \mathrm{~mm}$, considering the surface roughness coefficient of the volcanic ash particle $\left(1.07^{-1}\right)$ relative to its fall velocity (Bagheri and Bonadonna, 2016). 
Author contributions. MI and MM designed the study. AY and TM collected the samples and performed the free-fall experiment. SHS modified the original study topic and performed the study. MM and SHS performed research, obtained the results, and prepared the manuscript, along with contributions from all of the co-authors. DIL examined the results and checked the manuscript.

Competing interests. The authors declare that they have no conflict of interest.

Acknowledgements. The 2DVD data were provided by MEXT, Japan. We also thank the NIED for use of their large-rainfall simulator.

Financial support. This work was supported by a grant-in aid for JSPS KAKENHI (grant number JP16H03145) and partially supported by a DPRI collaborative research grant (Kyoto University grant no. 25G-11).

Review statement. This paper was edited by Alexander Kokhanovsky and reviewed by Masayuki Oishi and one anonymous referee.

\section{References}

Bagheri, G., Bonadonna, C., Manzella, I., Pontelandolfo, P., and Haas, P.: Dedicated vertical wind tunnel for the study of sedimentation of non-spherical particles, Rev. Sci. Instrum., 84, 054501, https://doi.org/10.1063/1.4805019, 2013.

Bagheri, G. and Bonadonna, C.: On the drag of freely falling nonspherical particles, Powder Technol., 301, 526-544, 2016.

Beckett, F., Witham, C., Hort, M., Stevenson, J., Bonadonna, C., and Millington, S.: Sensitivity of dispersion model forecasts of volcanic ash clouds to the physical characteristics of the particles, J. Geophys. Res.-Atmos., 120, 11636-11652, https://doi.org/10.1002/2015JD023609, 2015.

Bonadonna, C., Ernst, G., and Sparks, R.: Thickness variations and volume estimates of tephra fall deposits: the importance of particle Reynolds number, J. Volcanol. Geoth. Res., 81, 173-187, 1998.

Bonadonna, C., Genco, R., Gouhier, M., Pistolesi, M., Cioni, R., Alfano, F., Hoskuldsson, A., and Ripepe, M.: Tephra sedimentation during the 2010 Eyjafjallajökull eruption (Iceland) from deposit, radar, and satellite observations, J. Geophys. Res.-Sol. Ea., 116, B12202, https://doi.org/10.1029/2011JB008462, 2011.

Bonadonna, C., Folch, A., Loughlin, S., and Puempel, H.: Future developments in modelling and monitoring of volcanic ash clouds: outcomes from the first IAVCEI-WMO workshop on Ash Dispersal Forecast and Civil Aviation, B. Volcanol., 74, 1-10, 2012.

Böhm, H. P.: A general equation for the terminal fall speed of solid hydrometeors, J. Atmos. Sci., 46, 2419-2427, 1989.
Clift, R. and Gauvin, W.: Motion of particles in turbulent gas streams, Brit. Chem. Eng. Pr. Tec., 16, 439-448, 1971.

Coltelli, M., Miraglia, L., and Scollo, S.: Characterization of shape and terminal velocity of tephra particles erupted during the 2002 eruption of Etna volcano, Italy, B. Volcanol., 70, 1103-1112, 2008.

Del Bello, E., Taddeucci, J., Vitturi, M. d. M., Scarlato, P., Andronico, D., Scollo, S., Kueppers, U., and Ricci, T.: Effect of particle volume fraction on the settling velocity of volcanic ash particles: insights from joint experimental and numerical simulations, Sci. Rep., 7, 39620, https://doi.org/10.1038/srep39620, 2017.

Dellino, P., Mele, D., Bonasia, R., Braia, G., La Volpe, L., and Sulpizio, R.: The analysis of the influence of pumice shape on its terminal velocity, Geophys. Res. Lett., 32, L21306, https://doi.org/10.1029/2005GL023954, 2005.

Dioguardi, F., Mele, D., Dellino, P., and Dürig, T.: The terminal velocity of volcanic particles with shape obtained from 3-D X-ray microtomography, J. Volcanol. Geoth. Res., 329, 41-53, 2017.

Dioguardi, F., Mele, D., and Dellino, P.: A New One-Equation Model of Fluid Drag for Irregularly Shaped Particles Valid Over a Wide Range of Reynolds Number, J. Geophys. Res.-Sol. Ea., 123, 144-156, 2018.

Donnadieu, F.: Volcanological applications of Doppler radars: A review and examples from a transportable pulse radar in L-band, INTECH Open Access Publisher, 409-446, 2012.

Folch, A., Costa, A., and Macedonio, G.: FALL3D: A computational model for transport and deposition of volcanic ash, Comput. Geosci., 35, 1334-1342, 2009.

Ganser, G. H.: A rational approach to drag prediction of spherical and nonspherical particles, Powder Technol., 77, 143-152, 1993.

Garboczi, E. and Bullard, J.: 3D analytical mathematical models of random star-shape particles via a combination of X-ray computed microtomography and spherical harmonic analysis, Adv. Powder Technol., 28, 325-339, 2017.

Haider, A. and Levenspiel, O.: Drag coefficient and terminal velocity of spherical and nonspherical particles, Powder Technol., 58, 63-70, 1989.

Happel, J. and Brenner, H.: Low Reynolds number hydrodynamics: with special applications to particulate media, Springer Science \& Business Media, 1-543, 2012.

Harris, D. M. and Rose, W. I.: Estimating particle sizes, concentrations, and total mass of ash in volcanic clouds using weather radar, J. Geophys. Res.-Oceans, 88, 10969-10983, 1983.

Herzegh, P. H. and Jameson, A. R.: Observing precipitation through dual-polarization radar measurements, B. Am. Meteorol. Soc., 73, 1365-1376, 1992.

Hotta, K., Iguchi, M., and Tameguri, T.: Rapid dike intrusion into Sakurajima volcano on August 15, 2015, as detected by multiparameter ground deformation observations, Earth Planet. Sc. Lett., 68, 1-9, https://doi.org/10.1186/s40623-016-0450-0, 2016.

Hölzer, A. and Sommerfeld, M.: New simple correlation formula for the drag coefficient of non-spherical particles, Powder Technol., 184, 361-365, 2008.

Huang, G.-J., Bringi, V., Cifelli, R., Hudak, D., and Petersen, W.: A methodology to derive radar reflectivity-liquid equivalent snow rate relations using C-band radar and a 2-D video disdrometer, J. Atmos. Ocean. Tech., 27, 637-651, 2010. 
Huang, G.-J., Bringi, V., Moisseev, D., Petersen, W. A., Bliven, L., and Hudak, D.: Use of 2-D-video disdrometer to derive mean density-size and Ze-SR relations: Four snow cases from the light precipitation validation experiment, Atmos. Res., 153, 34-48, 2015.

Iguchi, M.: Magma Movement from the Deep to Shallow Sakurajima Volcano as Revealed by Geophysical Observations (< Special Section $>$ Sakurajima Special Issue), Bulletin of the Volcanological Society of Japan, 58, 1-18, 2013.

Jaffrain, J., Studzinski, A., and Berne, A.: A network of disdrometers to quantify the small-scale variability of the raindrop size distribution, Water Resour. Res., 47, 1-8, https://doi.org/10.1029/2010WR009872, 2011.

Joss, J. and Waldvogel A.: A spectrograph for the automatic analysis of raindrops, Pure Appl. Geophys., 69, 240-246, 1967.

Kruger, A. and Krajewski, W. F.: Two-dimensional video disdrometer: A description, J. Atmos. Ocean. Tech., 19, 602-617, 2002.

Kunii, D. and Levenspiel, O.: Fluidization Engineering, John Wiley, 8, 44-45, 1969.

Langmann, B., Folch, A., Hensch, M., and Matthias, V.: Volcanic ash over Europe during the eruption of Eyjafjallajökull on Iceland, April-May 2010, Atmos. Environ., 48, 1-8, 2012.

Löffler-Mang, M. and Joss. J: An optical disdrometer for measuring size and velocity of hydrometeors, J. Atmos. Ocean. Tech., 17, 130-139, 2000

Maki, M. and Doviak, R.: Volcanic ash size distribution determined by weather radar, 1810-1811, 2001.

Maki, M., Maesaka, T., Kozono, T., Nagai, M., Furukawa, R., Nakada, S., Koshida, T., and Takenaka, H.: Quantitative volcanic ash estimation by operational polarimetric weather radar, The 9th International Symposium on Tropospheric Profiling, L'Aquila, Italy, September 2012, ISBN 978-90-815839-4-7, 2012.

Maki, M., Maesaka, T., Muraji, Y., and Suzuki, I.: Statistical analysis of volcanic ash measured by X-band polarimetric radar, 8th European Conference on Radar in Meteorology and Hydrology, 15 September, 2014.

Maki, M., Iguchi, M., Maesaka, T., Miwa, T., Tanada, T., Kozono, T., Momotani, T., Yamaji, A., and Kakimoto, I.: Preliminary results of weather radar observations of sakurajima volcanic smoke, J. Disaster Res., 11, 15-30, 2016.

Marzano, F. S., Barbieri, S., Vulpiani, G., and Rose, W. I.: Volcanic ash cloud retrieval by ground-based microwave weather radar, IEEE T. Geosci. Remote, 44, 3235-3246, 2006.

Marzano, F. S., Picciotti, E., Vulpiani, G., and Montopoli, M.: Synthetic signatures of volcanic ash cloud particles from X-band dual-polarization radar, IEEE T. Geosci. Remote, 50, 193-211, 2012

Marzano, F. S., Picciotti, E., Montopoli, M., and Vulpiani, G.: Inside volcanic clouds: Remote sensing of ash plumes using microwave weather radars, B. Am. Meteorol. Soc., 94, 1567-1586, 2013.

Nešpor, V., Krajewski, W. F., and Kruger, A.: Wind-induced error of raindrop size distribution measurement using a two-dimensional video disdrometer, J. Atmos. Ocean. Tech., 17, 1483-1492, 2000.

Oguchi, T., Udagawa, M., Nanba, N., Maki, M., and Ishimine, Y.: Measurements of dielectric constant of volcanic ash erupted from five volcanoes in Japan, IEEE T. Geosci. Remote, 47, 10891096, 2009.
Poulidis, A. P., Takemi, T., Iguchi, M., and Renfrew, I. A.: Orographic effects on the transport and deposition of volcanic ash: A case study of Mount Sakurajima, Japan, J. Geophys. Res.Atmos., 122, 9332-9350, 2017.

Rong, L., Zhou, Z., and Yu, A.: Lattice-Boltzmann simulation of fluid flow through packed beds of uniform ellipsoids, Powder Technol., 285, 146-156, 2015.

Rosenfeld, D. and Ulbrich, C. W.: Cloud microphysical properties, processes, and rainfall estimation opportunities, in: Radar and Atmospheric Science: A Collection of Essays in Honor of David Atlas, Springer, 30, 237-258, 2003.

Seligman, A. N., Bindeman, I. N., Watkins, J. M., and Ross, A. M.: Water in volcanic glass: From volcanic degassing to secondary hydration, Geochim. Cosmochim. Ac., 191, 216-238, 2016.

Sheppard, B. E.: Measurement of raindrop size distributions using a small Doppler radar, J. Atmos. Ocean. Tech., 7, 255-268, 1990.

Sigurdsson, H., Houghton, B., McNutt, S., Rymer, H., and Stix, J.: The encyclopedia of volcanoes, Elsevier, 30, 1-1456, 2015.

Stevenson, J. A., Millington, S. C., Beckett, F. M., Swindles, G. T., and Thordarson, T.: Big grains go far: understanding the discrepancy between tephrochronology and satellite infrared measurements of volcanic ash, Atmos. Meas. Tech., 8, 2069-2091, https://doi.org/10.5194/amt-8-2069-2015, 2015.

Stokes, G. G.: On the effect of the internal friction of fluids on the motion of pendulums, Pitt Press Cambridge, 1-86, 1851.

Suzuki, T.: A theoretical model for dispersion of tephra, Arc volcanism: physics and tectonics, 95-113, 1983.

Takahashi, M., Otsuka, T., Sako, H., Kawamata, H., Yasui, M., Kanamaru, T., Otsuki, M., Kobayashi, T., Ishihara, K., and Miki, D.: Temporal Variation for Magmatic Chemistry of the Sakurajima Volcano and Aira Caldera Region, Southern Kyushu, Southwest Japan since $61 \mathrm{ka}$ and Its Implications for the Evolution of Magma Chamber System, Bulletin of the Volcanological Society of Japan, 58, 19-42, 2013.

Tajima, Y., Ohara, D., Fukuda, K., and Shimomura, S.: Development of Automatic Tephrometer for Monitoring of Volcano, 23, 39-46, 2015.

Thurai, M. and Bringi, V.: Drop axis ratios from a 2-D video disdrometer, J. Atmos. Ocean. Tech., 22, 966-978, 2005.

Tokay, A., Wolff, D. B., and Petersen, W. A.: Evaluation of the new version of the laser-optical disdrometer, OTT Parsivel2, J. Atmos. Ocean. Tech., 31, 1276-1288, 2014.

Tran-Cong, S., Gay, M., and Michaelides, E. E.: Drag coefficients of irregularly shaped particles, Powder Technol., 139, 21-32, 2004.

Van Eaton, A. R., Muirhead, J. D., Wilson, C. J., and Cimarelli, C.: Growth of volcanic ash aggregates in the presence of liquid water and ice: an experimental approach, B. Volcanol., 74, 1963-1984, 2012.

Waterman, P. C.: Symmetry, unitarity, and geometry in electromagnetic scattering, Phys. Rev. D, 3, 825, https://doi.org/10.1103/PhysRevD.3.825, 1971.

Wilson, L. and Huang, T.: The influence of shape on the atmospheric settling velocity of volcanic ash particles, Earth Planet Sc. Lett., 44, 311-324, 1979.

Wilson, T. M., Stewart, C., Sword-Daniels, V., Leonard, G. S., Johnston, D. M., Cole, J. W., Wardman, J., Wilson, G., and Barnard, S. T.: Volcanic ash impacts on critical infrastructure, Phys. Chem. Earth, 45, 5-23, 2012. 
Wilson, T. M., Jenkins, S., and Stewart, C.: Impacts from volcanic ash fall, in: Volcanic Hazards, Risks and Disasters, Elsevier, 2015.
Yokoo, A. and Ishihara, K.: Volcanic activity around Showa Crater of Sakurajima Volcano monitored with infrared and video cameras, Annuals of Disas. Prev. Res. Inst., Kyoto Univ., No. 50 C., 2007. 